\title{
Synaptic Vesicle Redistribution During Hippocampal Frequency Potentiation and Depression in Young and Aged Rats
}

\author{
Michael D. Applegate ${ }^{a}$ and Philip W. Landfield \\ Department of Physiology \& Pharmacology, Bowman Gray School of Medicine, Winston-Salem, North Carolina 27103
}

Technical complexities associated with studies of defined synapses in the mammalian CNS have made it difficult to determine whether CNS synaptic vesicles respond to repetitive monosynaptic activation in the same ways as do PNS vesicles. Moreover, even in the PNS, the specific ultrastructural correlates of short-term synaptic potentiation are not well characterized. In the present studies, therefore, the Schaffer collateral-commissural fiber projection to field CA1 of the hippocampus was used as a model brain system in which to assess quantitative relations between dynamic vesicle patterns and frequency potentiation and depression. Anesthetized rats were perfused with aldehyde fixative during stimulation trains and concomitant microelectrode recording in order to study temporal correlations between physiology and synaptic structure. In addition, young and aged animals were compared to determine whether there are ultrastructural correlates of a previously described agerelated impairment of hippocampal frequency potentiation.

After $1 \mathrm{~min}$ of $10 \mathrm{~Hz}$ synaptic stimulation (stim), frequency potentiation of the population spike was correlated with increases in local vesicles (LV; within $150 \mathrm{~nm}$ of the active zone) and in vesicles directly apposed (AV) to the active zone membrane of CA1 synapses. In addition, the ratio LVD: DVD of local-to-distant vesicle (DV; beyond $150 \mathrm{~nm}$ ) densities was increased under all stimulation conditions. After $10 \mathrm{~min}$ of $10 \mathrm{~Hz}$ stim, or $1 \mathrm{~min}$ of $40 \mathrm{~Hz}$ stim, some vesicle depletion (approximately $25 \%$ ) was present, as was some spike depression or decline from peak potentiation. However, LV depletion was not well correlated with degree of spike depression. Mean dendritic spine area was also increased in association with potentiation (at $1 \mathrm{~min}$ of $10 \mathrm{~Hz}$ stim) in young rats. Membrane infoldings similar to the cisternae described in other systems were seen with repetitive stimulation, providing evidence of vesicle recycling in these CNS terminals.

In comparison to young control animals, terminals in nonstimulated aged control rats exhibited a higher LVD:DVD ratio and a reduced DVD. In addition, the stimulation-induced increase in AV at $1 \mathrm{~min}$ of $10 \mathrm{~Hz}$ stim was not present in

Received Dec. 18, 1986; revised Aug. 12, 1987; accepted Sept. 23, 1987.

We thank S. Vinsant, L. Cadwallader, and D. S. Kerr for extremely valuable and extensive technical contributions. This work was supported by grant AG 04542 .

Correspondence should be addressed to Dr. P. W. Landfield, Bowman Gray School of Medicine, Department of Physiology \& Pharmacology, 300 South Hawthorne Road, Winston-Salem, NC 27103

- Present address: Department of Pathology, Johns Hopkins University School of Medicine, 600 North Wolfe Street, Baltimore, MD 21205.

Copyright (C) 1988 Society for Neuroscience $0270-6474 / 88 / 041096-16 \$ 02.00 / 0$ aged rat synapses. However, no age-related differences in vesicle-density measures were found at any stimulation point.

Thus, the data indicate that CNS vesicles generally respond similarly to PNS vesicles, that CNS vesicle patterns are correlated with frequency potentiation, but are not well correlated with spike depression, and that aspects of the dynamic vesicle response (e.g., the AV increase) differ with age; however, a general age-related decline in vesicle density does not seem to account for the age-related Impairment of hippocampal frequency potentiation. Therefore, some factor in addition to vesicle density (e.g., postsynaptic spine changes, inactivation of presynaptic $\mathrm{Ca}^{2+}$ current) appears to modulate CNS synaptic efficacy during repetitive activation.

Because of the overlap of synaptic fields and other complexities of the mammalian CNS, it has been difficult to study synaptic vesicle correlates of the activation of a wcll-defincd set of CNS synapses. Only a relative handful of studies have quantified synaptic vesicle changes in defined CNS synapses in response to either repetitive monosynaptic stimulation (e.g., Fifkova and Van Harreveld, 1977; Landfield et al., 1979; Desmond and Levy, 1986; Applegate et al., 1987), polysynaptic sensory stimulation (Fehér et al., 1972), or widespread brain activation (e.g., Langmeier et al., 1983).

Although vesicle depletion was observed in several of those CNS studies, most did not examine the distribution of vesicles within synaptic terminals. Consequently, it is not clear whether synaptic vesicles in the mammalian CNS exhibit patterns of activation-dependent redistribution to the active zone and of recycling, analogous to those of vesicles in the PNS (cf. Heuser and Reese, 1973, 1977) and in some fish central systems (Model et al., 1975; Maler and Mathieson, 1985).

Moreover, even in the PNS, there have been only a few studies on vesicle responses to stimulation trains that specifically induce synaptic potentiation. The few prior potentiation-vesicle studies, conducted either in peripheral systems (Jones and Kwanbunbumpen, 1970; Quilliam and Tamarind, 1973) or in mammalian brain (e.g., Fifkova and Van Harreveld, 1977; Landfield et al., 1979; Desmond and Levy, 1986; Applegate et al., 1987), generally found an increase in the proportion of vesicles near the active zone ("local" vesicles). In those experiments, however, only postactivation forms of potentiation were studied and only synapses fixed at some time point following the end of the stimulation train were assessed ultrastructurally. Therefore, it is unclear whether the fixation of synapses during a stimulation train might reveal additional ultrastructural responses (e.g., an increase of vesicles attached to the active zone membrane, $\mathrm{cf}$. Dickenson-Nelson and Reese, 1983), and/or might permit quan- 
titative studies of correlations between dynamic ultrastructural patterns and concurrent short-term synaptic potentiation.

Central "frequency potentiation" (FP; the growth of synaptic responses during a repetitive stimulation train; cf. Andersen and Lømo, 1967) appears to function as a mechanism for amplifying biologically significant information (i.e., information transmitted at higher frequencies), and therefore could be critical in the processing and storage of such information. For example, an age-related deficit in hippocampal FP has been found (Landfield et al., 1978, 1983, 1986) that conceivably might be a factor in the well-established (e.g., Arenberg and Robertson-Tchabo, 1977), age-dependent decline in the capacity for processing higher-frequency information.

Nonetheless, the cellular mechanisms underlying central FP are still not fully understood. That is, although short-term potentiation in peripheral or invertebrate systems (e.g., "frequency facilitation") has been found to depend on increased transmitter release (Martin, 1977), it is not certain that similar processes operate in the mammalian CNS. Problems resulting from possible nonstationarity or nonuniformity of release probability (e.g., Zucker, 1973; Brown et al., 1976; Smith, 1980), and from the attenuation of dendritic EPSPs (Rall and Rinzel, 1973; Brown and Johnston, 1983; Turner, 1988), have made it difficult to draw definitive conclusions from quantal analyses in central systems (cf. Kuno, 1964; Mendell and Weiner, 1976; Hirst et al., 1981; McNaughton et al., 1981; Neale et al., 1983). Further, repetitive stimulation in the hippocampus induces changes in several postsynaptic variables that can influence EPSP amplitude, including membrane potential, inhibitory regulation, spine configuration, and receptor density (e.g., Andersen and Lomo, 1967; Schwartzkroin, 1975; Fifkova and Van Harreveld, 1977; MacVicar and Dudek, 1979; Lee et al., 1980; Wilson et al., 1981; Desmond and Levy, 1983; Chang and Greenough, 1984; Lynch and Baudry, 1984; McCarren and Alger, 1985; Turner, 1988). Consequently, while generalized postsynaptic membrane shifts apparently do not underlie FP in the hippocampus (cf. Pitler and Landfield, 1987a), the possibility of a localized postsynaptic contribution (e.g., by spines or receptors) to short-term CNS synaptic plasticity has not yet been ruled out.

Thus, if vesicle patterns are correlated to some degree with transmitter release patterns, the analysis of CNS vesicle patterns should yield significant insights into mechanisms of normal or abnormal synaptic plasticity. The vesicle hypothesis of quantal release (i.e., that one vesicle equals one quantum; Katz, 1962) remains somewhat controversial (cf. Tauc, 1982); however, regardless of whether or not the hypothesis is fully correct, substantial evidence from pcriphcral systems indicates that (1) vesicle populations are generally correlated with synaptic transmitter content; (2) vesicle populations are partly maintained during stimulation by rapid recycling, but vesicles can be depleted by intense or prolonged activation; and, as noted, (3) vesicles migrate to the active zone during repetitive activation (e.g., Heuser and Reese, 1973; Pysh and Wiley, 1974; Model et al., 1975; Zimmerman and Denston, 1977; Maler and Mathieson, 1985; see reviews in Heuser and Reese, 1977; Ceccarelli and Hurlbut, 1980). Moreover, recent studies using rapid freeze techniques or fixation during stimulation found extremely close temporal and quantitative correlations between vesicle fusion to the presynaptic membrane and release of transmitter (Dickenson-Nelson and Reese, 1983; Haimann et al., 1985; Torri-Tarelli et al., 1985).

These correlations suggest that vesicle studies might provide useful information that cannot be obtained at present by physiological studies alone, on the bases of CNS frequency potentiation and on the mechanisms of the age-related deficit in such potentiation. Age-related decreases have been found in synaptic vesicles (Landfield et al., 1979) or $\mathrm{Ca}^{2+}$-containing vesicles (Fifkova and Cullen-Dockstader, 1986) in rat hippocampus. In addition, reduced transmitter content with no decline of vesicles (Smith and Rosenheimer, 1982; Smith, 1984), or reduced vesicles (Fahim and Robbins, 1982), have been found at aged rat or aged mouse neuromuscular junctions, respectively. However, dynamic vesicle responses during repetitive stimulation have not been studied in detail in relation to aging.

Conducting studies of vesicle correlates of short-term CNS synaptic plasticity is dependent upon the accessibility of a welldefined CNS synaptic system capable of strong and persistent frequency potentiation, and on the use of methods that permit tissue fixation during a stimulation train. The hippocampus is one of the few brain structures in which internal pathways and synaptic fields are sufficiently distinct and homogeneous (e.g., Hjorth-Simonsen, 1972; Gottlieb and Cowan, 1973; Steward, 1976; Swanson et al., 1978) to permit analyses of vesicle responses in defined systems. In addition, the mammalian hippocampus is characterized both by extremely long-lasting postactivation potentiation ("long-term potentiation") and by highly robust "frequency potentiation" (cf. Bliss and Lømo, 1973; Andersen, 1975).

In the present studies, therefore, stimulation-induced vesicle patterns in field CAl of the hippocampus were quantified in both young adult and aged rats in order to address 3 basic questions: (1) Do mammalian CNS vesicles exhibit dynamic responses to repetitive stimulation that are analogous to the responses of PNS vesicles? (2) Are there consistent ultrastructural synaptic correlates of frequency potentiation in this model system? and (3) Are there age-related differences in vesicle dynamics that are correlated with age-related differences in hippocampal FP?

Some of these data have been described in abstract form (Applegate and Landfield, 1985).

\section{Materials and Methods}

Subjects were male, Fischer 344 albino rats from the specific pathogenfree colony of the National Institute on Aging. A total of 39 animals in 8 groups [i.e., 4 groups of young-mature (3-5-months-old) and 4 groups of aged (24-27-months-old) animals in each of 4 experimental conditions; see below] were included in this study. Aged animals exhibiting overt pathology and animals that exhibited clear seizures during the stimulation were excluded from the study.

Stimulation and recording. All animals were anesthetized with injections of urethane $(1.2 \mathrm{gm} / 6 \mathrm{ml}$ saline $/ \mathrm{kg}$, i.p. $)$ and given supplemental doses $(0.5 \mathrm{ml})$ when needed to maintain uniform deep anesthesia. The recording microelectrode $(60 \mu \mathrm{m}$ diameter, enameled tungsten, etched at the tip to approximately $1 \mathrm{M} \Omega$ impedance) was lowered to the CAl pyramidal cell somal layer, and the stimulating electrode ( $200 \mu \mathrm{m}$ O.D., bipolar coated stainless steel) was lowered to the Schaffer commissural fibers of field CA3. This well-defined pathway primarily contains Schaffer collateral and commissural fibers and courses in a restricted region from CA 3 to the dendrites of CA1 pyramidal cells. Its densest termination is in approximately the middle third of the CAl apical dendrites in stratum radiatum (Gottlieb and Cowan, 1973; Swanson et al., 1978). The coordinates for the electrodes were as follows: recording: $3.5 \mathrm{~mm}$ posterior to bregma, $2.0 \mathrm{~mm}$ lateral to the midline, approximately 2.0 $\mathrm{mm}$ deep from the brain surface (as determined by extracellular action potentials from stratum pyramidale); stimulation: $3.5 \mathrm{~mm}$ posterior to bregma, $3.5 \mathrm{~mm}$ lateral to the midline (angled $15^{\circ}$ toward the midline), approximately $2.7 \mathrm{~mm}$ deep from the brain surface. Minor adjustments 


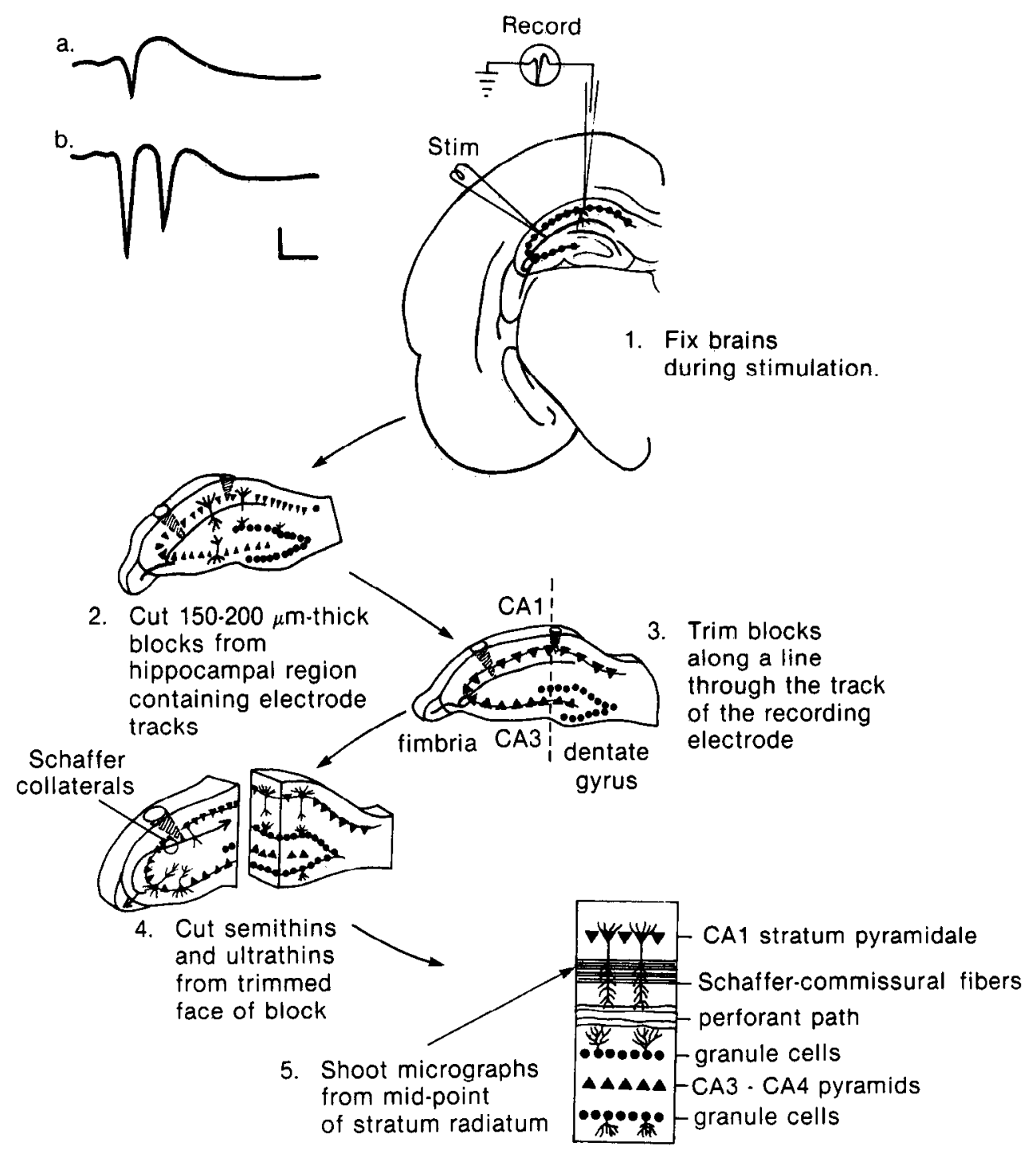

Figure 1. Schematic illustration of experimental procedures. Stimulation and recording electrodes were positioned according to stereotaxic and electrophysiological criteria to stimulate the Schaffer-commissural pathway and record the monosynaptic $\mathrm{CA} 1$ pyramidal cell population spike (inset). Inset, $a$, control spite; $b$, spike frequency potentiation during $10 \mathrm{~Hz}$ stimulation. Brains were fixed by intracardial perfusion during stimulation and recording. Hippocampal sections were prepared from a highly restricted and consistent region of the stratum radiatum, as illustrated in the diagram.

were made to take into account skull size differences, and the final localization was based on both physiological and stereotaxic criteria (cf. Andersen, 1975; Landfield et al., 1978). The recording microelectrode was incorporated within a self-contained, chronic microdrive assembly (cf. Deadwyler et al., 1979). Once the characteristic stratum pyramidale CA1 population spike response to monosynaptic Schaffer-commissural stimulation was obtained (upper left, Fig. 1), both the recording assembly and the stimulating electrode were cemented to the skull. The microdrive assembly allowed further electrode adjustment to obtain optimal responses after transfer to the perfusion apparatus and prior to the onset of the stimulation protocol. These procedures allow the electrophysiological state to be monitored during both stimulation and fixation, and allowed stimulation to be maintained during the delivery of fixative.

The 4 stimulation conditions in this study were (1) for sham-operated control animals, implantation but not exposure to repetitive stimulation (young, $n=7$; aged, $n=5$ ); (2) 1 min stimulation-perfusion after approximately $1 \mathrm{~min}$ of $10 \mathrm{~Hz}$ stimulation (young, $n=6$; aged, $n=5$ ); (3) 10 min stimulation-perfusion after approximately $10 \mathrm{~min}$ of $10 \mathrm{~Hz}$ stimulation (young, $n=5$; aged, $n=6$ ); and (4) $40 \mathrm{~Hz}$-perfusion after approximately $1 \mathrm{~min}$ of $40 \mathrm{~Hz}$ stimulation (young, $n=3$; aged, $n=2$ ).

Although the population EPSP in the dendrites of CA1 (an extracellular summation of individual EPSPs) reflects synaptic efficacy more directly than does the stratum pyramidale population spike (an extracellular summation of individual action potentials; cf. Andersen, 1975), repetitive stimulation at intensities above population spike threshold in the hippocampus usually induces near-total depression of the population EPSP (unpublished observations). Since intracellular studies of
FP (Landfield et al., 1986; Pitler and Landfield, 1987a) indicate that the intracellular EPSP is still strongly potentiated at time points at which the extracellularly recorded population EPSP is depressed, this depression of the field EPSP appears to be due not to synaptic depression, but to extracellular $\mathrm{K}^{+}$accumulation (e.g., Prince et al., 1973; Alger and Teyler, 1978), and resultant wide depolarization and altered source-sink relations in the extracellular field (e.g., Humphrey, 1968; Rall and Shepherd, 1968). However, extracellular population spike amplitude in the CAl somal layer is not as affected as is the population EPSP by repetitive stimulation, perhaps because of a more restricted and larger sink (Andersen, 1975). Therefore, since population spike amplitude is also reasonably well correlated with intracellular EPSP amplitude during repetitive stimulation (e.g., Andersen, 1975; Schwartzkroin, 1975; MacVicar and Dudek, 1979; Landfield et al., 1986; Pitler and Landfield, 1987a), we used population spike amplitude as an approximate estimate of synaptic function. Positioning the recording electrode in the cell somal layer (stratum pyramidale), rather than in stratum radiatum, yielded the added benefit of reduced tissue damage from the electrode to the relevant synaptic fields (stratum radiatum).

After the animals were placed in the perfusion apparatus in a position compatible both with stimulation and intracardial perfusion, a final readjustment of electrode localization was made. An input-output stimulation series was then run, and the stimulation intensity was set at $150 \%$ of population spike threshold. This intensity was maintained throughout the stimulation paradigm (however, to prevent seizures, intensity was briefly reduced (e.g., for 3-10 sec) if nonstimulus-locked spikes appeared, since these can signal an impending seizure]. After 20 $30 \mathrm{sec}$ of stimulation, surgery for intracardial perfusion was initiated 
for animals in the 1 min groups. The fixative solution reached the brain (as determined by population spike depression) at approximately $1 \mathrm{~min}$ of stimulation. In the 10 min groups, surgery was begun after approximately $9.5 \mathrm{~min}$ of stimulation and fixative reached the brain at about $10 \mathrm{~min}$. To control against possible distortion of the electrophysiological values from the surgical procedures, spike amplitudes were measured just prior to the initiation of surgery. Recordings were also obtained throughout the fixation to determine whether seizures occurred ( 3 young and 2 aged rats exhibited major seizures or abnormal responses during either stimulation or fixation, and were excluded from the final analysis of 39 animals).

Fixation and sample selection. During perfusion, the abdomen was opened, the descending abdominal aorta was clamped with a hemostat to direct fixative solution toward the upper body, the rib cage and diaphragm were cut, and the right auricle was cut to allow drainage of fixative. The left ventricle was then catheterized and perfused at a rate of $30-40 \mathrm{ml} / \mathrm{min}$ (gravity feed). The entire surgical procedure took approximately $30-35 \mathrm{sec}$, and only $10-15 \mathrm{sec}$ elapsed between the time at which the diaphragm was cut and the time at which the solution entered the heart.

A $2 \%$ glutaraldehyde/ $2 \%$ paraformaldehyde fixative solution in a 0.15 $M$ sodium cacodylate buffer containing $1.0 \mathrm{~mm} \mathrm{Ca}{ }^{2+}$ and $1.0 \mathrm{~mm} \mathrm{Mg} \mathrm{Mg}^{2+}$ was perfused for 10-15 min, after which the brain was removed and stored overnight in fixative at $4^{\circ} \mathrm{C}$. Criteria for acceptable fixation quality were normal, unswollen mitochondria, sharp membranes with little intercellular space, and normal-appearing myelin. Two animals did not meet the minimum criteria for good fixation (judged blind) and were not included in the final total of 39 animals.

Fixed brains were serially sectioned into $250 \mu \mathrm{m}$ sections (Vibratome) until the electrode tracks were located. The tissue was then trimmed to yield a block containing the apical dendrites of the CAl pyramidal cells adjacent to the recording electrode; this block was then processed and embedded in Epon according to standard EM procedures. Subsequently, semithin and ultrathin sections were cut on a plane parallel to the apical dendrites and perpendicular to the cell somal layer. Twenty-five micrographs were shot from 3 randomly selected ultrathin sections from each animal (8-9 micrographs/section), at a strictly defined depth of CAl stratum radiatum (the measured midpoint between stratum pyramidale and the perforant path). The micrograph frames were evenly spaced and nonoverlapping, and covered the full section width at that depth; the spacing was similar for all sections. This sequence was changed only to a void very large dendritic shafts or glial processes (by moving one-half frame further across the section). Micrographs were photographically enlarged from an initial magnification of $25,000 \times$ to a final magnification of $70,000 \times$ for quantitative analysis. Synapses selected for analysis included all those for which the paramembranous density (active zone), terminal, and spine were fully included on the micrographs.

Quantitative methods. Synaptic terminals and associated dendritic spines were analyzed using a digitizing pad and a computerized morphometric analysis system (Bioquant) to obtain area and perimeter measurements. For each synapse, the length of the active zone, the total presynaptic terminal area and perimeter, the terminal area within 150 $\mathrm{nm}$ of any point of the active zone, and the spine area and perimeter were measured.

Synapses were separated initially into several categories (e.g., simple axospinous, perforated, dendritic shaft, and multiple spine). However, all categories showed highly similar patterns and, consequently, the categories were combined in order to simplify presentation of the results. Multiple-spine synapses (i.e., 2 spines associated with one bouton) were treated as 2 synapses for vesicle analysis, and the area of the bouton was divided by a line from the rear membrane of the terminal, drawn equidistant between the 2 active zone densities. These synapses accounted for only approximately $5 \%$ of the total. Perforated synapses were treated as a single density (e.g., Peters et al., 1976).

Synaptic vesicles were counted in the whole terminal (total vesicles: TV) and in the area within $150 \mathrm{~nm}$ of any point on the active zone (local vesicles: LV) (cf. Jones and Kwanbunbumpen, 1970; Quilliam and Tamarind, 1973; Dickenson-Nelson and Reese, 1983; Maler and Mathieson, 1985). The distant vesicle (DV) values were derived from the other counts (TV - LV). Vesicles in direct contact with the presynaptic membrane of the active zone (attached vesicles: AV) were also counted. The LV, DV, and TV were converted to densities (LVD, DVD, and TVD) by dividing vesicle counts by relevant areas. In addition, an LVD:DVD ratio was calculated for each terminal as an index of the
Population Spike Amplitude

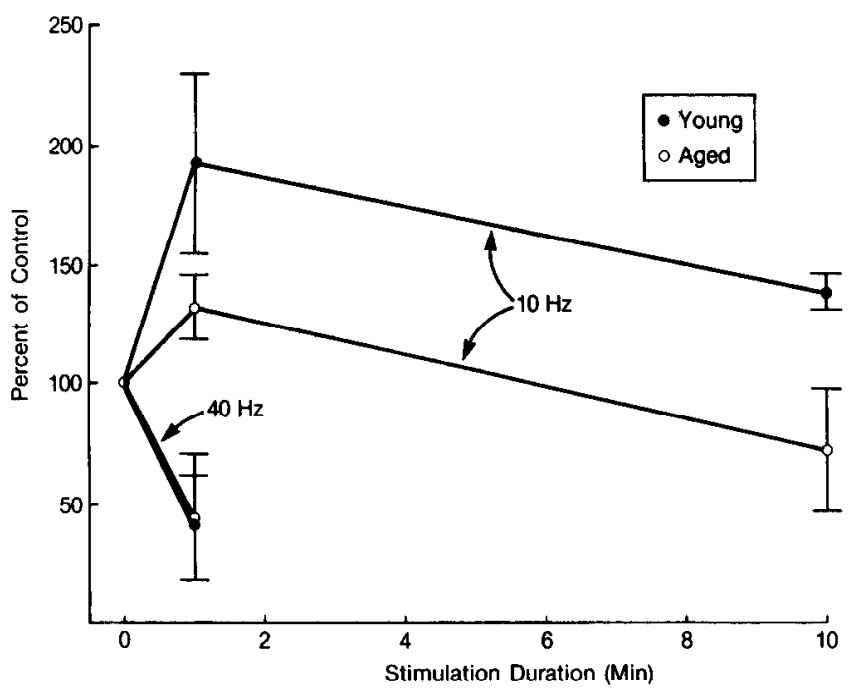

Figure 2. Percentage changes in population spike amplitude in the 10 and $40 \mathrm{~Hz}$ stimulation conditions, as functions of both age and stimulation duration (means \pm SEM).

tendency for vesicles to be distributed near the active zone. All analyses were conducted "blind" on coded micrographs.

Nearly 4000 terminals and 150,000 vesicles were analyzed by these procedures (i.e., approximately 100 terminals and 3500 vesicles from each of 39 animals). In addition, the diameters of a randomly selected sample (grid overlay method) of synaptic vesicles (approximately 3-4\% of the total number), distributed proportionately between the LV and DV populations, were measured with a $7 \times$ magnifying lens marked in $0.1 \mathrm{~mm}$ increments. Final effective magnification was $490,000 \times$ with a measurement precision of approximately $1.5 \mathrm{~nm}$.

A stereological correction factor based on vesicle size (Weibel, 1979) was applied to the vesicle counts of several animals, but there were no group differences in vesicle diameter, and the extremely small individual differences and variability in vesicle size (cf. Table 3 ) led to corrections of less than 1\%; therefore a correction factor for vesicle diameter was not generally applied in the overall analysis.

Each variable was averaged across terminals to provide a single mean terminal value per animal, and the statistical population was therefore equal to number of animals. Moreover, in order to determine whether the mean terminal results were diluted or inaccurate because results from large numbers of nonactivated terminals obscured large effects of stimulation on small populations of selectively activated terminals, the data were also analyzed for the frequency of activated and depleted terminals for each animal. An activated terminal was defined as one with an LVD:DVD ratio above 2.5 , and a depleted terminal was defined as one containing less than 100 total vesicles $/ \mu \mathrm{m}^{2}$. Two-way analyses of variance (ANOVAs) were used to assess all morphometric variables, and individual group contrasts were tested with Bonferroni post hoc tests. Stepwise multiple regressions were used to assess the relationship between electrophysiological and morphological variables (HSD software).

\section{Results}

Electrophysiology

The frequency potentiation of the population spike seen during repetitive stimulation was similar to that found in previous studies (Andersen and Lømo, 1967), and the observed age-related deficits in frequency potentiation (Fig. 2), were also similar to those seen in earlier studies (Landfield et al., 1978, 1983, 1986). Young animals showed robust potentiation at $1 \mathrm{~min}$ of $10 \mathrm{~Hz}$ stimulation, which gradually decaycd from pcak levels with continued stimulation. Aged animals exhibited relatively 


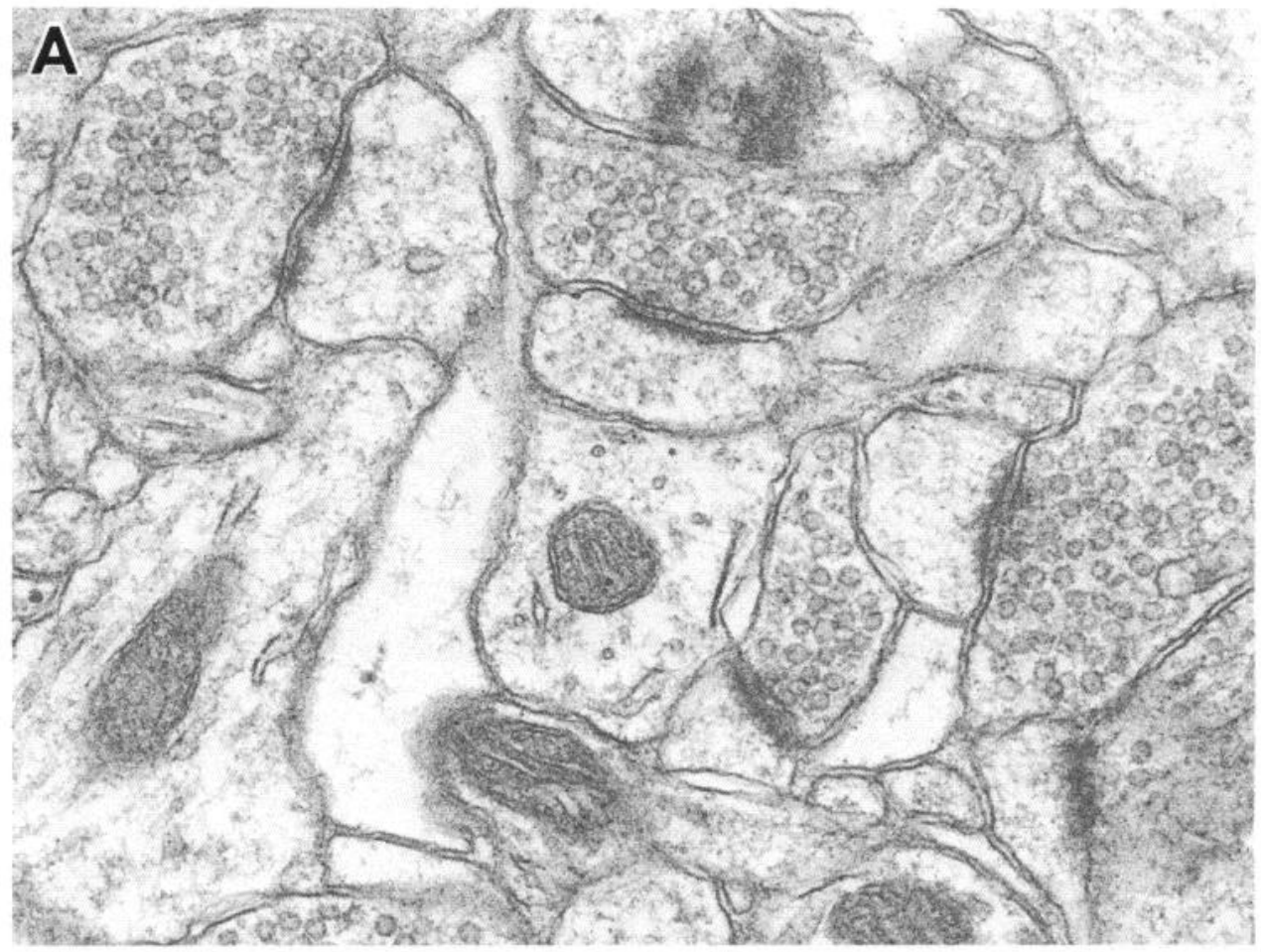

Figure 3. Representative electron micrographs from aged and young control animals. $A$, Control condition in a young animal, showing uniform and dense distribution of synaptic vesicles within the terminals. $B$, Control condition in an aged animal, showing some terminals with densely and uniformly distributed vesicles, and other terminals with relatively reduced numbers of vesicles. $\times 56,250$.

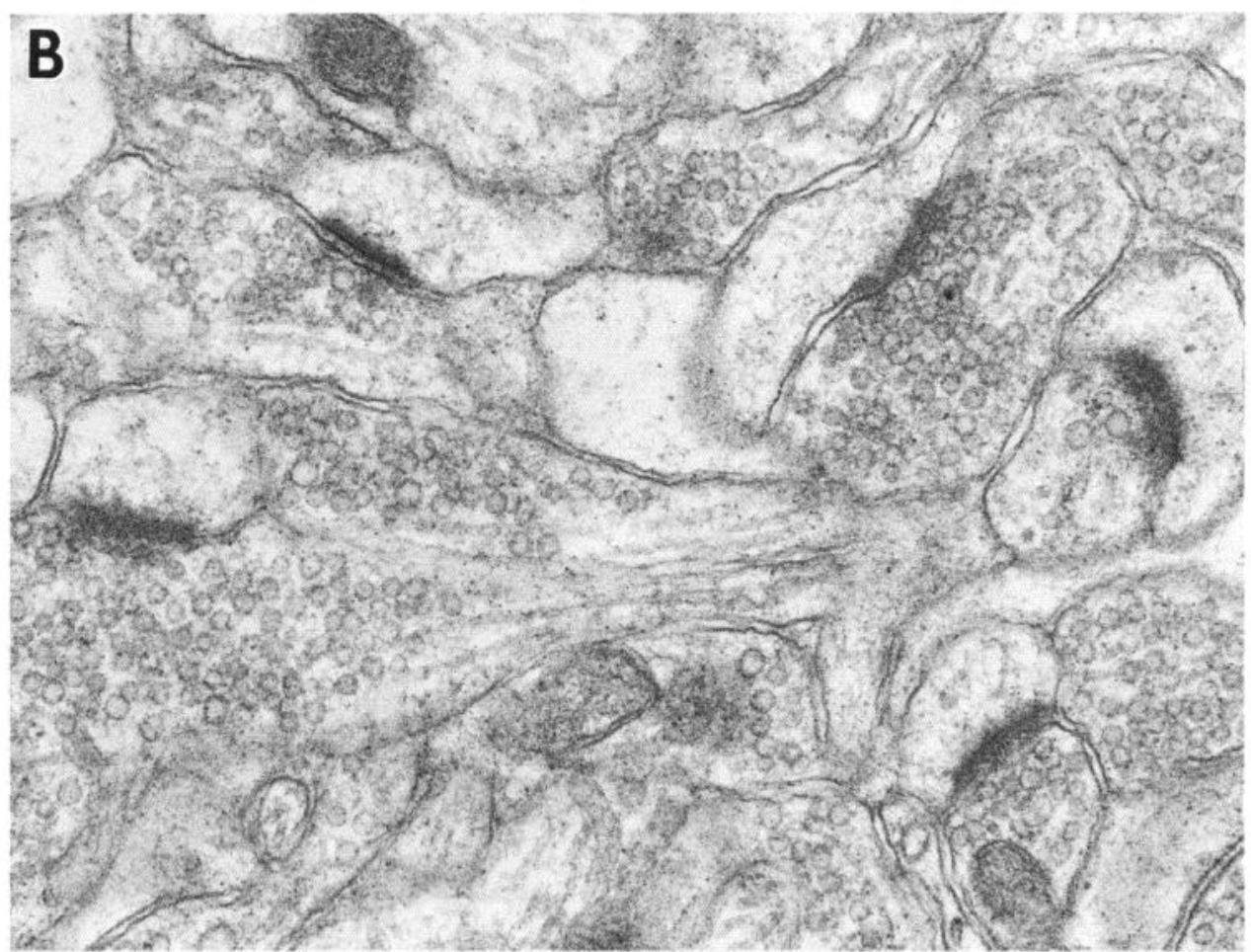

less potentiation at $1 \mathrm{~min}$ and greater depression at the later time point (Fig. 2). An ANOVA with split-plot design showed a significant main effect of age on spike potentiation $(F=4.8$; $p=0.05)$ and a highly significant main effect of duration of stimulation $(F=11.9 ; p=0.008)$. With $1 \mathrm{~min}$ of $40 \mathrm{~Hz}$ stimulation there were no differences in population spike amplitude between young ( $43 \pm 25 \%)$ and aged $(40 \pm 22 \%)$ animals, but the values in both groups were significantly depressed below control $(p=0.02)$.
Measurements of the latency between the stimulus artifact and the onset of the population spike revealed no age differences, but did show a large effect of stimulation on latency $(F=22.9$; $p<0.001)$. Latency increased from approximately $130 \%$ of control at $1 \mathrm{~min}$ to nearly $210 \%$ at $10 \mathrm{~min}$. The latency from stimulus artifact to population spike onset in the $40 \mathrm{~Hz}$ groups also did not differ as a function of age, but increased as a function of stimulation. The latency values for the $1 \mathrm{~min}, 40 \mathrm{~Hz}$ groups were generally similar to those in the $10 \mathrm{~min}, 10 \mathrm{~Hz}$ groups. 

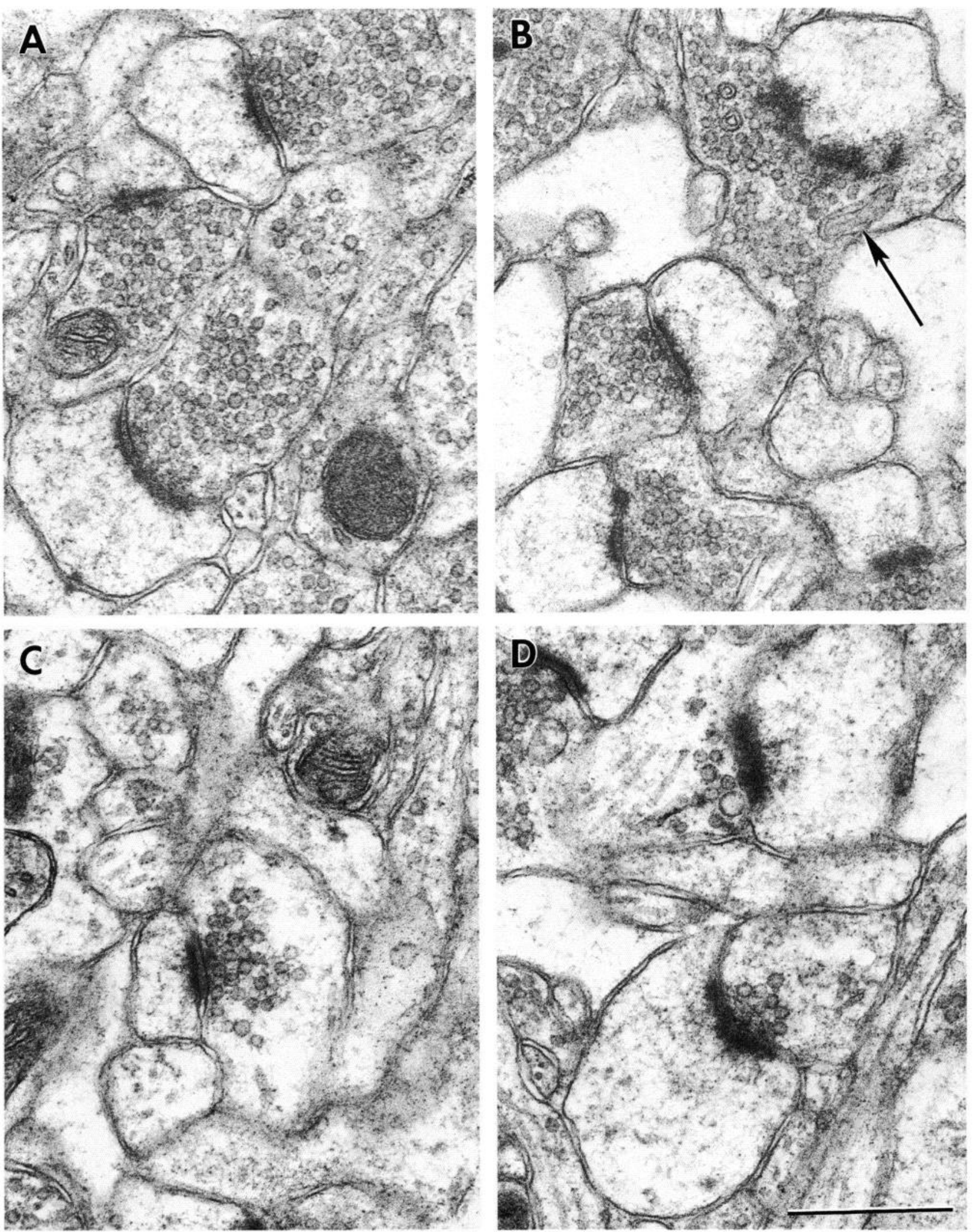

Figure 4. Representative electron micrographs from young animals administered $1 \mathrm{~min}$ or $10 \mathrm{~min}$ of $10 \mathrm{~Hz}$ stimulation. $A, B$, Examples of terminals from a young animal after $1 \mathrm{~min}$ of $10 \mathrm{~Hz}$ stimulation, showing a greater proportion of vesicles near the synaptic active zone than in the control state (Fig. 3) and no depletion. $C, D$, Examples of terminals from a young animal after $10 \mathrm{~min}$ of $10 \mathrm{~Hz}$ stimulation, showing relative depletion in conjunction with a continued shift of vesicles toward the active zone. Arrow in $B$, Infolding in terminal that also includes other double membranous vesicle-like profiles. $\times 62,500$. Calibration line, $0.5 \mu \mathrm{m}$. 


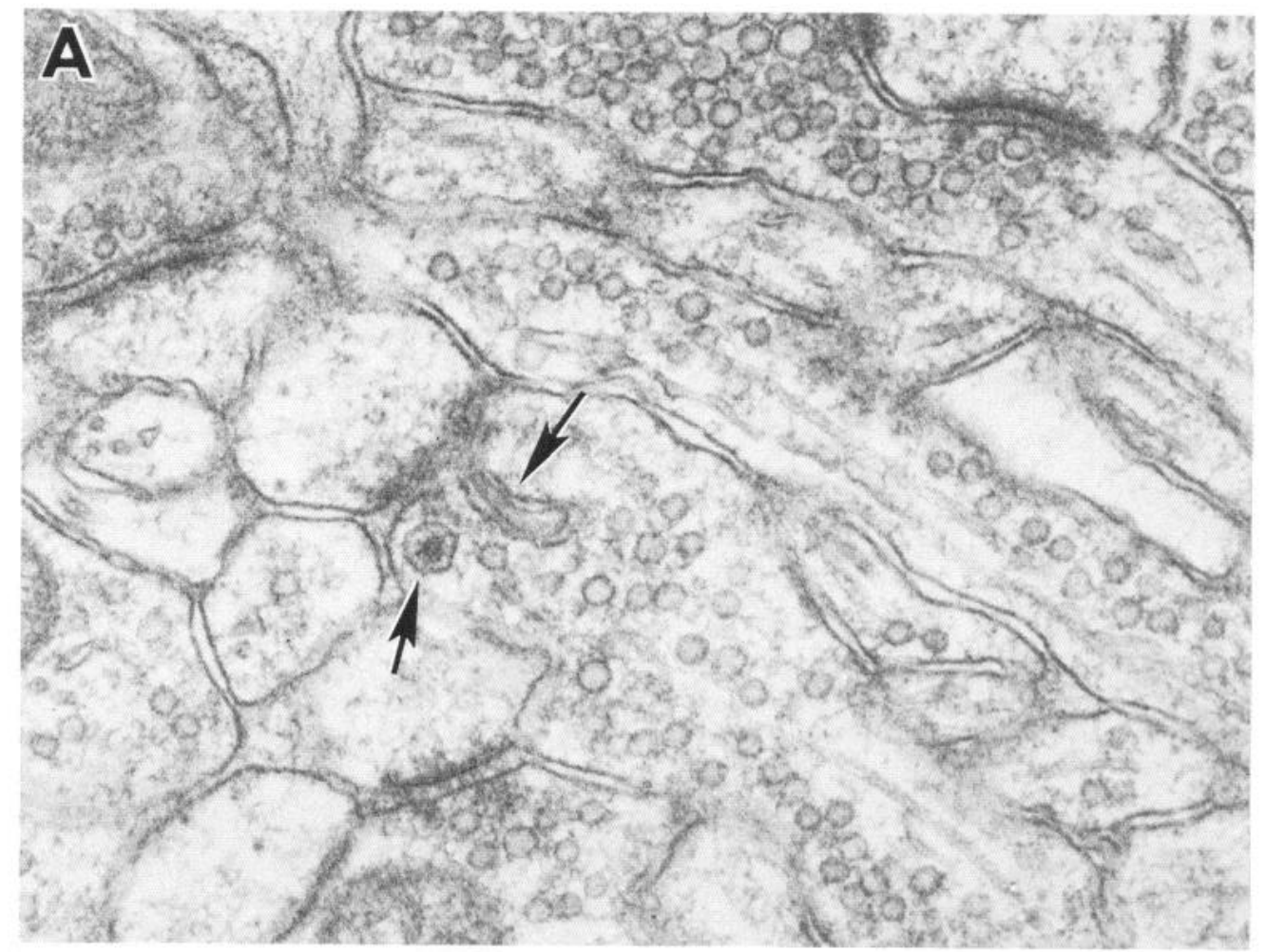

Figure 5. Examples from animals stimulated at $40 \mathrm{~Hz}$ for $1 \mathrm{~min}$, illustrating parallel double membrane infoldings of the presynaptic terminal membrane (arrows). With the exception of one example in $A$, these infoldings usually appeared to be derived from nonactive-zone membrane $(B)$. Such infoldings may be analogous to the cisternae described by Heuser and Reese (1973) in the periphery, or to the paired membranous cisternae described by Model et al. (1975) in Mauthner cells, and may be a source of recycled vesicles that replenish the distant vesicle population. $\times 70,000$.

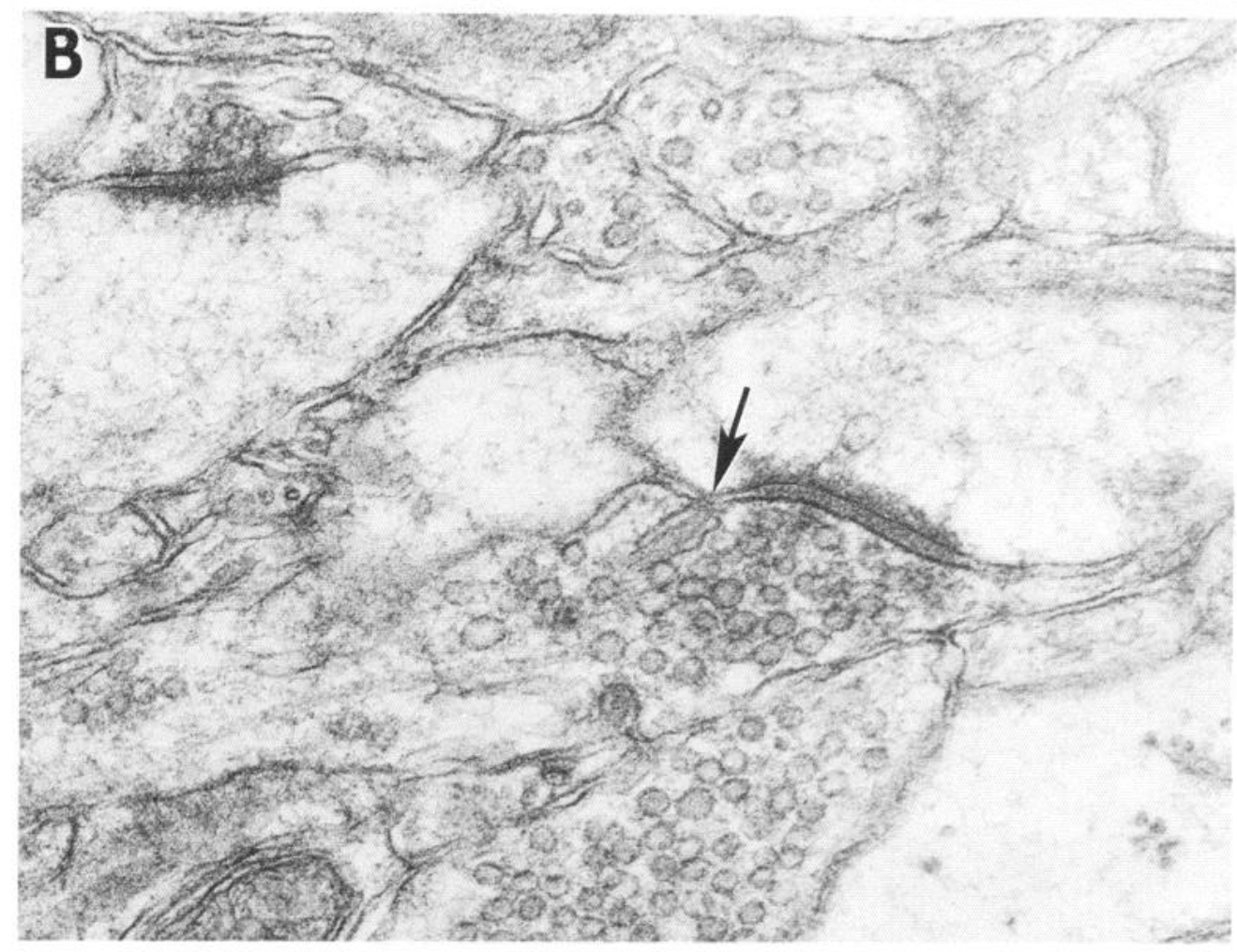

\section{Qualitative ultrastructural appearance}

Age-related differences in synaptic ultrastructure were not obvious by visual inspection alone, although in some cases, apparent differences could be seen in the control condition (e.g., Fig. 3). However, in animals administered repetitive stimulation, altered vesicle distribution patterns were pronounced, and differences from the control condition were clearly visible (Fig.
4). In comparison to controls, the terminals of stimulated animals were characterized by a larger proportion of total vesicles distributed near the active zone (Fig. 4, $A, B$ ). Further, in activated terminals the vesicles were often "lined up" in rowlike patterns perpendicular to the active zone, which gave the vesicles an appearance of "streaming" toward the presynaptic membrane (Fig. 4). After 10 min of stimulation, the shift of vesicles toward the active zone was accompanied in some an- 

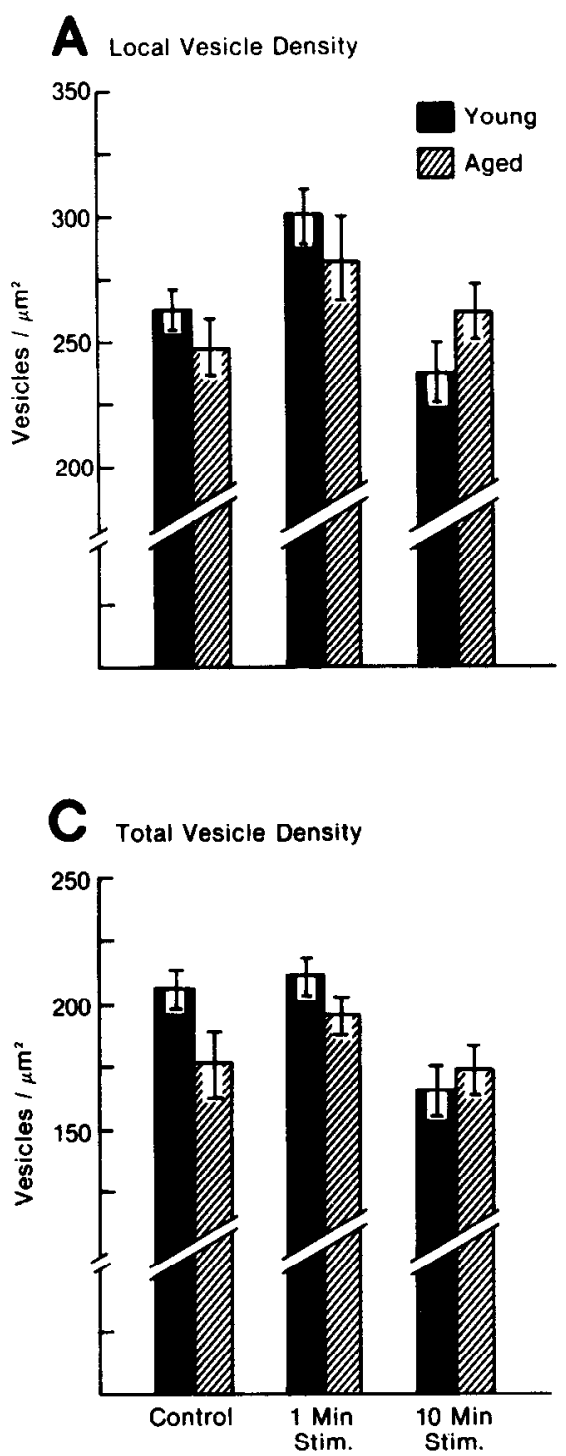

\author{
8 Distant Vesicle Density
}

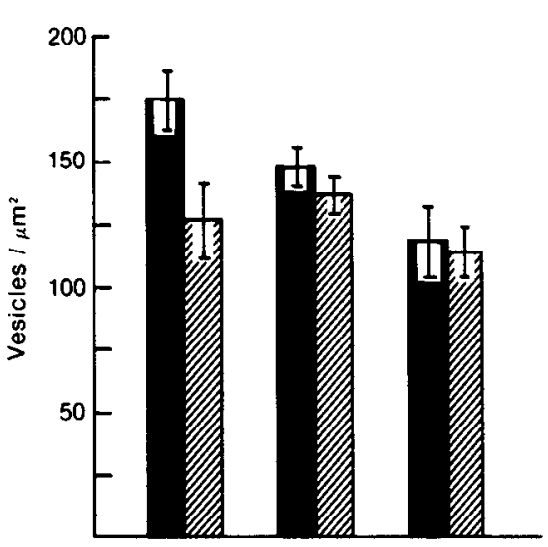

Local: Distant Ratio

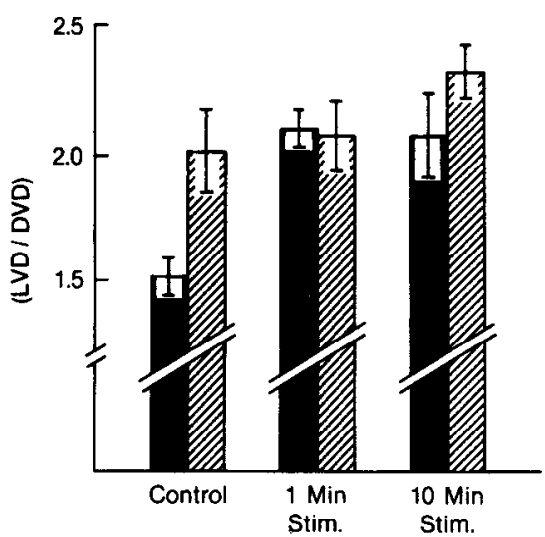

Figure 6. Synaptic vesicle densities as a function of $10 \mathrm{~Hz}$ stimulation. $A$, The density of local vesicles (LVD), which includes all vesicles within $150 \mathrm{~nm}$ of the active zone, was increased above control at the 1 min stimulation point, and returned to control levels or below at the $10 \mathrm{~min}$ point. No age differences were found. $B$, The density of distant vesicles (DVD), which includes all vesicles more than $150 \mathrm{~nm}$ from the synaptic density, declined from control at the 1 and $10 \mathrm{~min}$ points in young animals. In comparison, aged-rat terminals exhibited a significantly lower control DVD and showed only minor changes in DVD during stimulation. $C$, The density of total vesicles in the synaptic terminal (TVD) was significantly decreased at the $10 \mathrm{~min}$ point, in a pattern similar to that of the decrease of the DVD $(B) . D$, The local vesicle density : distant vesicle density ratio (LVD: DVD) reflects the degree of redistribution of vesicles to the active zone. There was substantial redistribution in young rat synapses during stimulation (higher ratio in stimulated groups), whereas the aged control animals began at a more "activated" level in comparison to young, and only minor further activation occurred in stimulated aged groups (nIeans \pm SEM). imals by an apparent depletion in the density of vesicles (Fig. $4, C, D)$. The terminals of animals stimulated at $40 \mathrm{~Hz}$ for 1 min appeared to exhibit as much depletion and shift of vesicles as did those of the $10 \mathrm{~min}, 10 \mathrm{~Hz}$ group. In addition, large infoldings of the terminal membrane were apparent in some terminals from the $40 \mathrm{~Hz}$ animals (Fig. 5). Infoldings were also seen, although somewhat less frequently, under $10 \mathrm{~Hz}$ stimulation conditions (Fig. $4 B$ ).

Despite these general patterns, however, not all terminals in this region derive from those specific Schaffer commissural fibers being stimulated, and, therefore, of course, tissue from each animal contained terminals reflecting a wide spectrum of vesicle patterns.

\section{Quantitative ultrastructural analyses}

A highly significant main effect of $10 \mathrm{~Hz}$ stimulation was found on LVD, which was due primarily to an elevation of LVD at the 1 min point. There was no main effect of age on LVD (Fig. $6 A$, Table 1).

DVD exhibited both stimulation and age effects. The DVD declined progressively from the control to the 1 and $10 \mathrm{~min}$
Table 1. Summary of $10 \mathrm{~Hz}$ statistical analyses

\begin{tabular}{lll} 
Variable & Main effects & Significant contrast effects \\
\hline TVD & $\begin{array}{l}\text { Age, } p=\text { N.S. } \\
\text { Stim, } p<0.01\end{array}$ & $\mathrm{Y}_{10}<\mathrm{Y}_{\mathrm{C}}, \mathrm{Y}_{1}$ \\
& Age, $p=$ N.S. & \\
LVD & Stim, $p<0.001$ & $\mathrm{Y}_{1}>\mathrm{Y}_{\mathrm{C}}, \mathrm{Y}_{10} ; A_{1}>A_{C}, \mathrm{~A}_{10}$ \\
DVD & Age, $p<0.02$ & $\mathrm{Y}_{\mathrm{C}}>\mathrm{A}_{C}$ \\
& Stim, $p<0.01$ & $\mathrm{Y}_{\mathrm{C}}>\mathrm{Y}_{1}, \mathrm{Y}_{10}$ \\
LVD:DVD & Age, $p<0.02$ & $\mathrm{Y}_{\mathrm{C}}<\mathrm{A}_{C}$ \\
& Stim, $p<0.002$ & $\mathrm{Y}_{\mathrm{C}}<\mathrm{Y}_{1}, \mathrm{Y}_{10}$ \\
AV & Age, $p=0.10$ & \\
& Stim, $p<0.01$ & $\mathrm{Y}_{1}>\mathrm{Y}_{\mathrm{C}}, \mathrm{Y}_{10}$
\end{tabular}

The main statistical findings for the group mean terminal values shown in Figure 6 are summarized here. $Y_{C}, Y_{1}$, and $Y_{10}$ are young animals in the control, $1 \mathrm{~min}$ stimulation groups, and 10 min stimuation groups, respectively; $A_{c}, A_{1}$, and $A_{10}$ represent the same groups for aged rats. See text for definitions of other terms. The statistical results for each variable were determined by 2 -way ANOVA (main effects), and the significant individual contrasts were determined by Bonferroni analyses of the ANOVA data. 

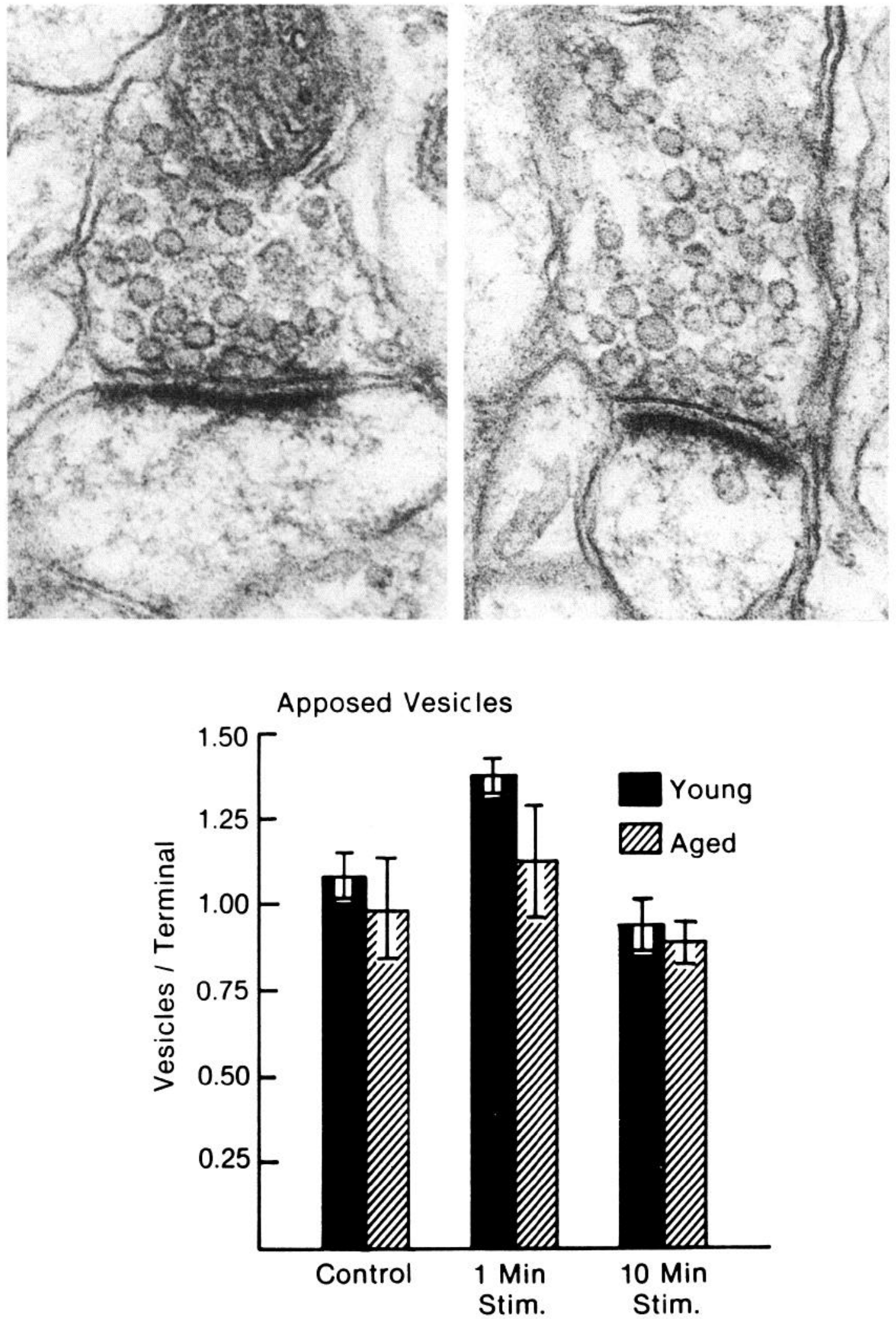

Figure 7. Top, Two examples of terminals with vesicles in contact with (attached or apposed to) the active zone membrane. $\times 115,000$. Bottom, Quantitative patterns of $10 \mathrm{~Hz}$-stimulation-induced changes in attached vesicles (means $\pm \mathrm{SEM}$ ). Apposed/attached vesicles (AV) were defined as those vesicles directly contacting the presynaptic membrane associated with the active zone (paramembranous density). In young animals, apposed vesicles were increased above control levels at the 1 min point. 
points in young animals. However, DVD was significantly lower in aged than in young animals in the resting control condition, and remained relatively stable in aged animals after 1 and 10 min of stimulation (Fig. $6 \mathrm{~B}$, Table 1).

As shown in Figure $6 C$, the TVD, which reflects both LVD and DVD, was significantly decreased after $10 \mathrm{~min}$ of stimulation (Table 1). This pattern was generally similar to that seen for the DVD. However, the main effect of age on TVD was not quite significant (Table 1).

The LVD:DVD ratio was significantly elevated in terminals of aged control animals, in comparison to the young controls (Fig. $6 D$ ). In the young animals, this ratio was significantly elevated by $10 \mathrm{~Hz}$ stimulation relative to resting controls, but in aged rat terminals, the ratio was little changed by stimulation from its already high (activated) control level (cf. Table 1).

Figure 7 shows examples of vesicles apposed or attached to the active zone membrane (top), and shows that the number of apposed vesicles (AV) per terminal was significantly increased above control levels at the $1 \mathrm{~min}, 10 \mathrm{~Hz}$ point, but was not different from the control level at the $10 \mathrm{~min}, 10 \mathrm{~Hz}$ point. The increase in AV at $1 \mathrm{~min}$ was significant only for the young group (Table 1).

\section{Analysis of activated and depleted terminals}

As noted above, the results of synaptic vesicle-density values could of course be influenced substantially if data from a large number of terminals that were not affected by the stimulation were included in the above analyses of mean values. On the other hand, if most terminals in the analyzed dendritic fields had been affected by the stimulation, and responded relatively homogeneously, then the results obtained by counting only the frequencies of activated or depleted terminals should be generally analogous to those obtained by assessing mean terminal values.

To address this issue, the percentage of activated and depleted terminals was calculated for each animal (cf. Materials and Methods), and group comparisons were again assessed by ANOVAs. The results are shown in Table 2. For activated terminals, we observed again both significant age and $10 \mathrm{~Hz}$ stimulation effects; the age differences were due largely to differences in the control values. For depleted terminals, the results of these analyses also showed a highly significant depletion (increase in depleted terminals) after $10 \mathrm{~min}$ of stimulation. As in the mean terminal analysis, no age difference was observed in total vesicle depletion. However, a nearly significant age $x$ stimulation interaction was present because there were more depleted terminals in aged rat synapses in the control condition, but fewer after $10 \mathrm{~min}$ of stimulation.

The results of these analyses (Table 2) generally agree with those from the mean terminal value analyses (Table 1), and it therefore seems likely that most terminals in the analyzed field were at least partially activated by the stimulation. This conclusion would be consistent with the extensive radiation and termination along the $\mathrm{CAl}$ apical dendrites of the Schaffer commissural fibers (e.g., Gottlieb and Cowan, 1973; Andersen, 1975; Swanson et al., 1978).

\section{Other ultrastructural variables}

A summary of data for the other morphological variables quantified in the $10 \mathrm{~Hz}$ studies is given in Table 3. No significant changes were found in active zone length, terminal shape factor,
Table 2. Percentage of activated and depleted terminals, $10 \mathrm{~Hz}$

Control $1 \mathrm{Min} \quad 10 \mathrm{Min}$

\begin{tabular}{|c|c|c|c|}
\hline \multicolumn{4}{|c|}{ A. Activated terminals (\%) } \\
\hline Young & $6.89 \pm 1.55$ & $14.47 \pm 2.58$ & $18.18 \pm 3.71$ \\
\hline Aged & $15.60 \pm 4.6$ & $18.60 \pm 1.92$ & $22.07 \pm 2.56$ \\
\hline \multicolumn{4}{|c|}{ B. Depleted terminals (\%) } \\
\hline Young & $4.44 \pm 2.08$ & $6.08 \pm 1.71$ & $20.54 \pm 4.42$ \\
\hline Agcd & $12.16 \pm 4.35$ & $8.64 \pm 1.63$ & $14.08 \pm 5.12$ \\
\hline
\end{tabular}

The mean percentage ( \pm SEM) of activated $(A)$ and depleted $(B)$ terminals for each of the groups. See text for definitions of activated and depleted terminals. For activated terminals, significant main effects were found for both stimulation $(F=$ $6.02, p=0.006)$ and age $(F=7.04, p=0.01)$. For depleted terminals, there was no main effect of age, but the effect of stimulation was highly significant $(F=6.1$, $p=0.006)$. The age $\times$ stimulation interaction was nearly significant $(F=2.60$, $p=0.09$ ).

terminal area, or vesicle diameter. However, mean area per spine showed a significant main effect of stimulation $(p=0.03)$ and a highly significant interaction term between age and stimulation $(p=0.006)$. Area per spine increased and then decreased during stimulation in the young animals, whereas it decreased steadily in aged rat synapses in relation to an already high control value.

\section{Forty Hertz stimulation}

The effects of $40 \mathrm{~Hz}$ stimulation on ultrastructural variables did not differ as a function of age in this study (Table 4). Nevertheless, $40 \mathrm{~Hz}$ stimulation for 1 min induced dramatic effects on terminal ultrastructure. In comparison to the $10 \mathrm{~Hz}, 1 \mathrm{~min}$ stimulation group (2-way ANOVA), each vesicle-density measure (TVD, LVD, DVD) was significantly lower for the $40 \mathrm{~Hz}$ animals (all $p$ 's $<0.001$ ). Other variables did not differ significantly between the $1 \mathrm{~min} 10$ and $40 \mathrm{~Hz}$ groups. As noted above, the $40 \mathrm{~Hz}$ groups were also characterized by more frequent examples of double membrane infoldings of terminal membrane (Fig. 5), similar to those seen at peripheral or Mauthner cell synapses after intense stimulation (Heuser and Reese, 1973; Model et al., 1975).

\section{Correlations of morphology with electrophysiology}

Using a stepwise multiple-regression method with an $F$ to enter of 2 and an $F$ to remove of 1.9 , the key ultrastructural variables were regressed onto the electrophysiological amplitude and latency data (measured at the stimulation time points just prior to the initiation of the surgery). The best combination of predictor variables for spike amplitude (percentage of control) included both DVD and TVD, which yielded a multiple correlation of 0.77 . Spike latency (percentage of control), which increased with prolonged stimulation and depression, was negatively correlated with most measures of vesicle density. The best combination of predictor variables for latency included LVD and length of the active zone. This combination yielded a negative multiple correlation of -0.69 . Figures 8 and 9 give examples of the relationship between the amplitude of the population spike and the density of synaptic vesicles in individual cases. Both figures were taken from the 2 animals in the $10 \mathrm{~min}$ stimulation group, which showed the greatest difference in electrophysiology, and therefore also illustrate the substantial variability in response that was found in aged animals. 
Table 3. Other ultrastructural variables

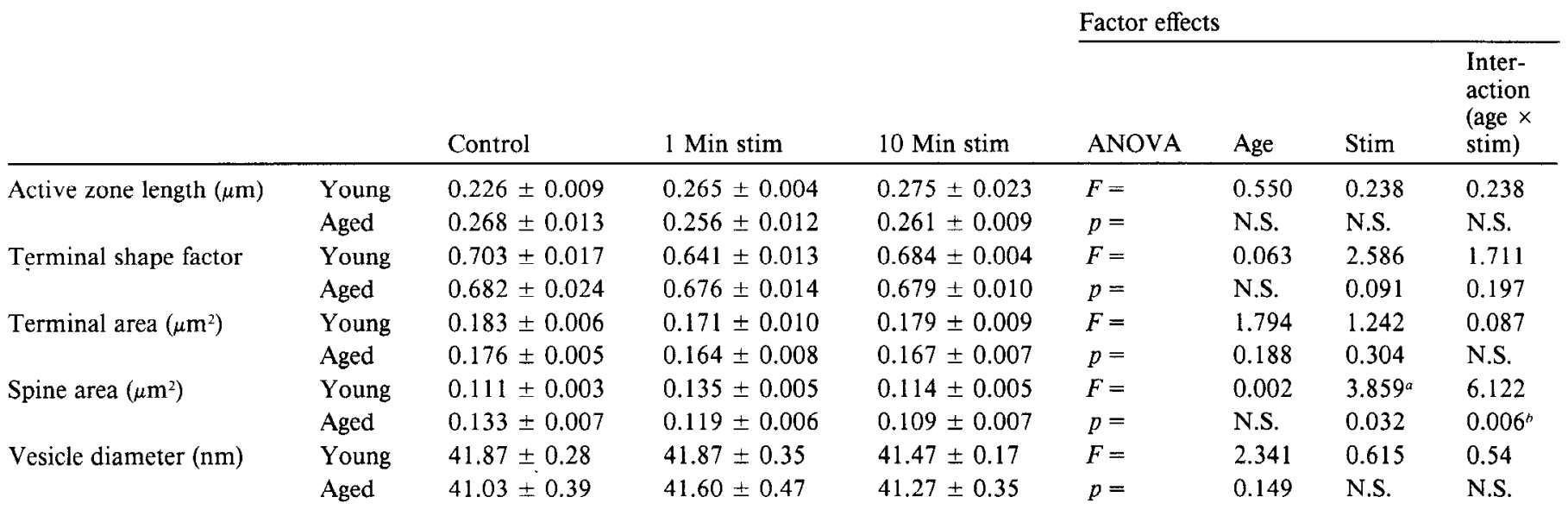

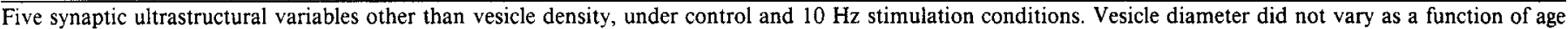

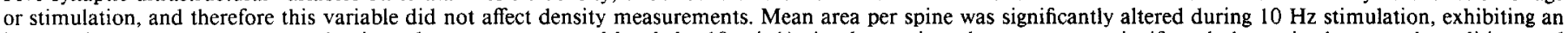

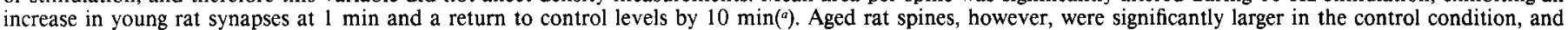
appeared to decline during $10 \mathrm{~Hz}$ stimulation $\left({ }^{b}\right)$. The $F$ and $p$ values from analyses of variance are shown. Shape factor was calculated according to the formula $(4 \pi$ area) $/\left(\right.$ perimeter $\left.^{2}\right)$, which gives a value of 1 when the profile is a circle. All values are means \pm SEM.

\section{Discussion}

\section{Relations of frequency potentiation and depression to vesicle patterns}

The results of this study provide generally affirmative answers to the main questions addressed. That is, repetitive monosynaptic stimulation of a defined mammalian brain system induced changes in the number and distribution of synaptic vesicles that were analogous to responses seen in peripheral synapses. Moreover, these vesicle changes were correlated with changes in the physiological function of the system, in particular, with the degree of short-term potentiation. At the point at which these synapses exhibited near-maximal potentiation of the response (1 min of the $10 \mathrm{~Hz}$ stimulation train), there was a significant increase in the LVD:DVD ratio, in the LVD, and in the number of vesicles attached to the active zone membrane. On the other hand, at points of reduced potentiation or of depression of the population spike response (e.g., after $10 \mathrm{~min}$ of $10 \mathrm{~Hz}$, or $1 \mathrm{~min}$ of $40 \mathrm{~Hz}$ ), there was a relative decline in each of these variables (except in the LVD:DVD ratio) back to, or below, control levels. Further, the DVD and TVD were decreased below resting control levels at these points of reduced potentiation or depression. The $40 \mathrm{~Hz}$ groups exhibited as much or more depression of the electrophysiological response and depletion of synaptic vesicles

Tahle 4. Effects of $40 \mathrm{~Hz}$

\begin{tabular}{lcc} 
Variable & Young & Aged \\
\hline TVD & $145.7 \pm 2.4$ & $165.4 \pm 14.2$ \\
LVD & $204.5 \pm 4.1$ & $225.9 \pm 18.9$ \\
DVD & $96.1 \pm 6.3$ & $102.8 \pm 6.3$ \\
LVD:DVD & $2.2 \pm 0.2$ & $2.2 \pm 0.1$ \\
AV (vesicles/terminal) & $1.2 \pm 0.1$ & $1.1 \pm 0.1$ \\
Spine area $\left(\mu \mathrm{m}^{2} /\right.$ spine $)$ & $0.12 \pm 0.01$ & $0.12 \pm 0.01$ \\
Active 7one length $(\mu \mathrm{m})$ & $0.24 \pm 0.006$ & $0.25 \pm 0.003$ \\
Vesicle diameter $(\mathrm{nm})$ & $42.6 \pm 0.5$ & $42.4 \pm 1.4$
\end{tabular}

Effects of $40 \mathrm{~Hz}$ stimulation for $1 \mathrm{~min}$ on ultrastructural variables in young and aged rats. Densities are expressed as vesicles $/ \mu \mathrm{m}^{2}$. All values are means $\pm \mathrm{SEM}$. None of the age differences was significant. See text for further definitions. as the $10 \mathrm{~min}, 10 \mathrm{~Hz}$ groups, despite a lesser number of total stimulation pulses. This result indicates that the observed vesicle changes depended more on the frequency than on the total number of stimulation pulses.

Nevertheless, there were some clear dissociations between patterns of vesicle depletion and the degree of depression. In particular, the spike response was still potentiated in the $10 \mathrm{~Hz}$, 10 min young group, despitc a decrease in vesicle density; conversely, the spike was severely depressed in the $40 \mathrm{~Hz}$ groups, although vesicle density was decreased only slightly more than in the $10 \mathrm{~Hz}, 10 \mathrm{~min}$ groups. This lack of correlation may only reflect the lack of precision of the population spike response as an index of synaptic function (e.g., the accumulation of extracellular $\mathrm{K}^{+}$would be expected to contribute to spike frequency potentiation during repetitive activation; cf. Prince et al., 1973; Alger and Teyler, 1978; Smith, 1980; Pitler and Landfield, 1987a). However, as discussed below, the low association of vesicle density with depression may instead reflect a major contribution of other factors to synaptic depression (e.g., postsynaptic factors, $\mathrm{Ca}^{2+}$ current inactivation, or nonfilled vesicles).

The data also did not provide strong evidence to support the hypothesis that vesicle-density differences underlie the age-related impairment in frequency potentiation. Although age differences were found in resting DVD, and in the AV during frequency potentiation, no age differences in $\mathrm{AV}$ were found at the $10 \mathrm{~min}$ point $(10 \mathrm{~Hz})$ at which population spike amplitude differed with age. Moreover, no age differences in vesicle density were found at any stimulation point. Again, this lack of correlation may reflect the shortcomings of indirect measures of synaptic function, or it may suggest the operation of factors other than vesicle density in controlling synaptic function (see below).

Despite these questions regarding depression and vesicle density, however, the present data appear to provide the first systematic evidence that the 4 main responses of peripheral system vesicle populations to monosynaptic repetitive stimulation (i.e., redistribution, attachment, recycling, and, at least to some degree, depletion; cf. Heuser and Reese, 1973, 1977; Ceccarelli and Hurlbut, 1980) are also found in the mammalian CNS. In addition, various aspects of these vesicle patterns in the hip- 


\section{CONTROL}

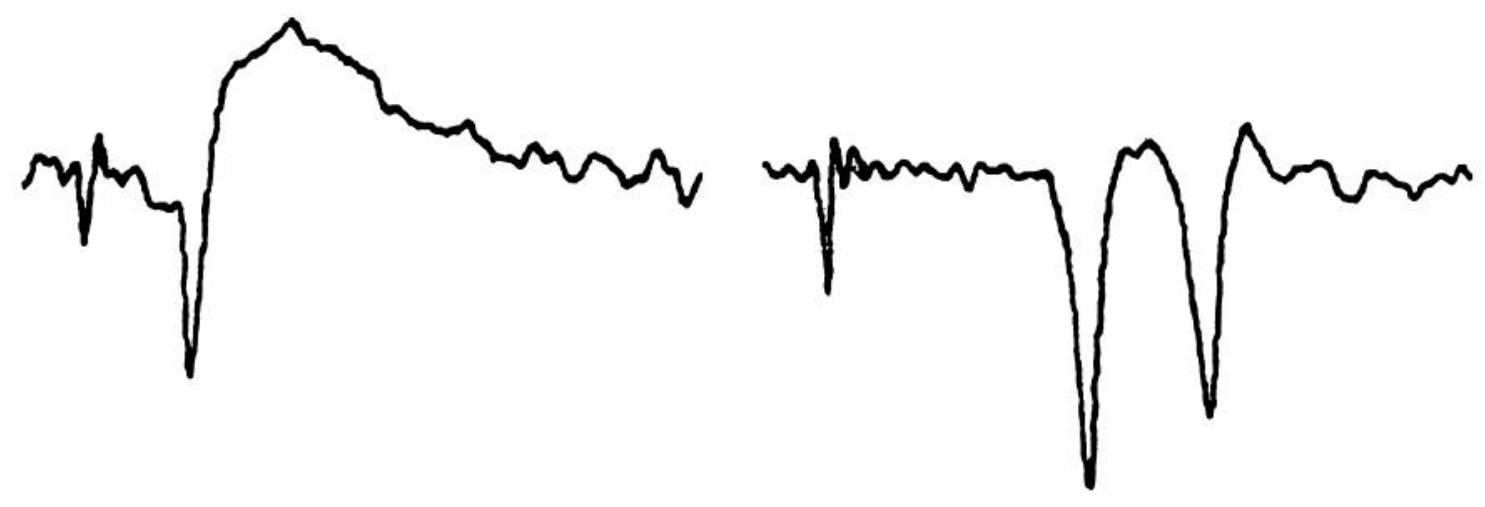

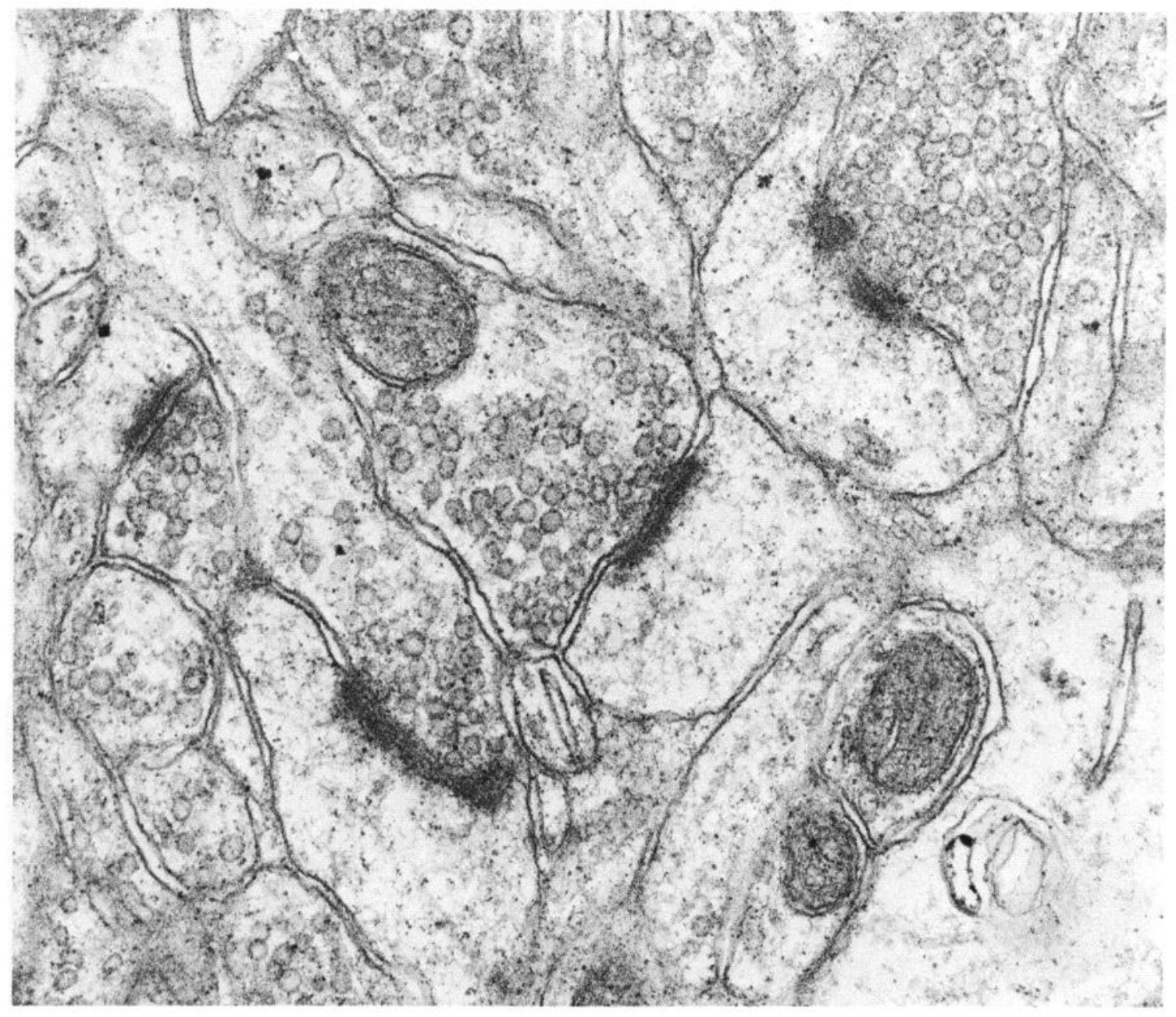

Figure 8. Hippocampal CA1 population spike (computer average of 5 responses) and representative electron micrograph, showing examples of the correlation between hippocampal physiology and presynaptic ultrastructure. The traces in this figure compare the control spike for this animal to the strong double-population spike still present after $10 \mathrm{~min}$ of stimulation. The micrograph is from this same animal at the $10 \mathrm{~min}$ point and shows "activated" synaptic terminals with relatively little depletion of synaptic vesicles. Compare to example in Fig. $9 . \times 70,000$. 


\section{CONTROL}

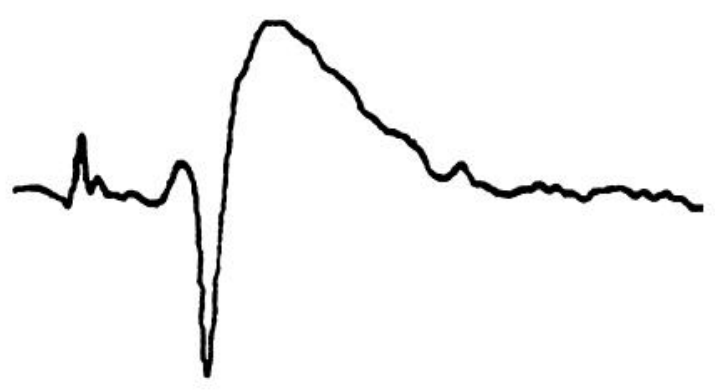

\section{MIN}

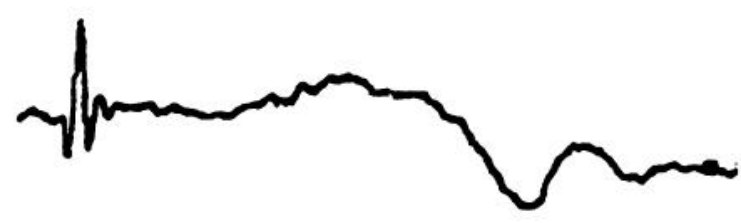

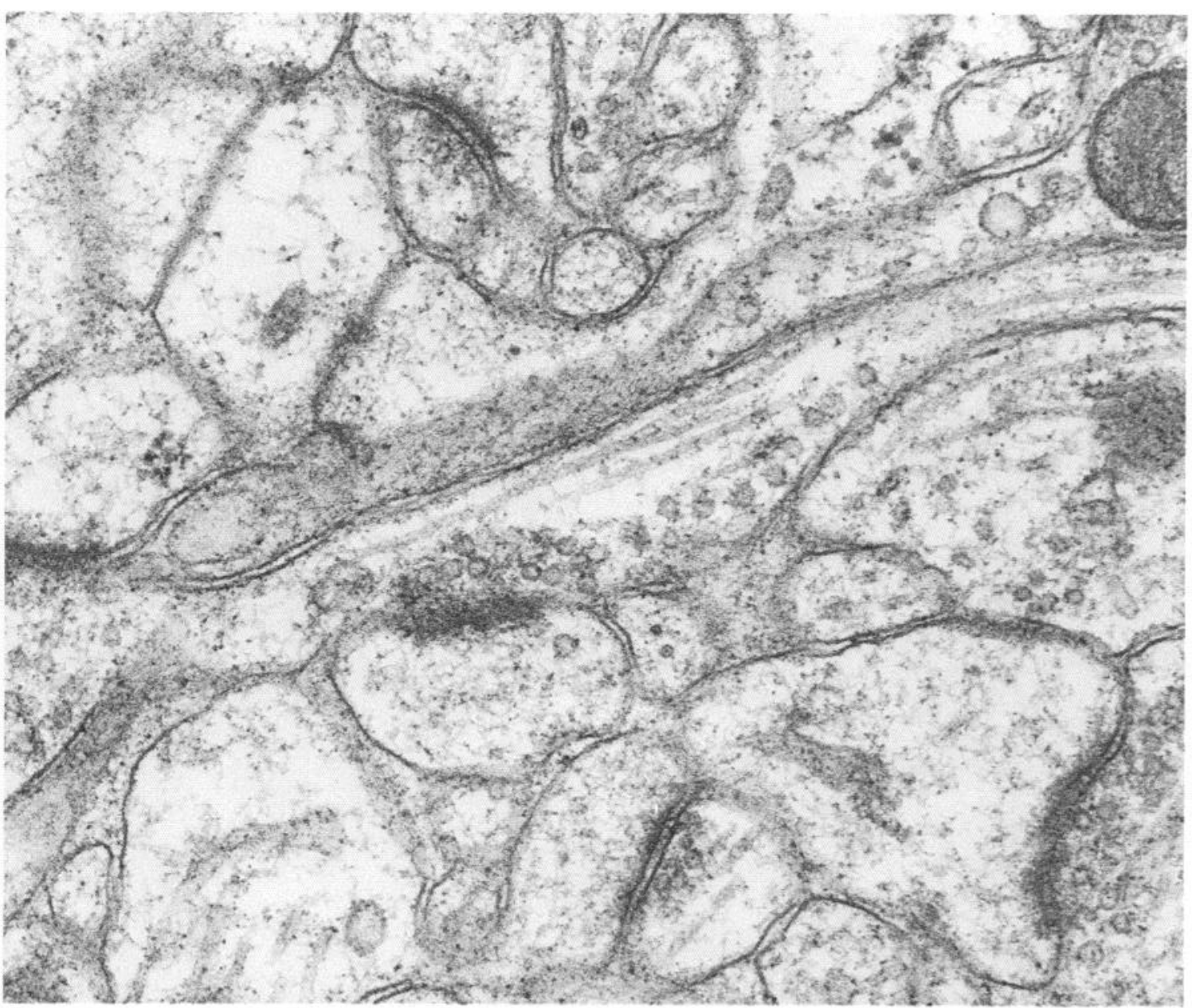

Figure 9. Traces of hippocampal CA1 averaged population spike from an aged animal that exhibited substantial depression of the population spike after $10 \mathrm{~min}$ of $10 \mathrm{~Hz}$ stimulation. Micrograph from the same animal at $10 \mathrm{~min}$ shows several terminals that are relatively depleted of synaptic vesicles. $\times 70,000$

pocampus are temporally and quantitatively correlated with short-term potentiation of neural function. However, correlational studies do not, of course, provide conclusive evidence that the observed vesicle changes underlie short-term potentiation and depression in the hippocampus.

\section{Possible confounding variables}

Even if it were possible to carry out more direct (e.g., intracellular) analyses of synaptic function in the intact animal, and even if the single vesicle/single quantum hypothesis were com- 
pletely correct, several factors might still confound the degree of correlation between measures of vesicle density/distribution and measures of synaptic function. One of these is the possible recycling and resynthesis of synaptic vesicles that are either too distant from release sites or are not sufficiently filled to influence synaptic transmission (e.g., Heuser and Reese, 1973; Zimmerman and Denston, 1977). It has been found, for example, that suppression of vesicle resynthesis with ouabain substantially improves the correlation between vesicle density and measured quantal content (Torri-Tarelli et al., 1985).

A second possible confounding factor might be $\mathrm{Ca}^{2+}$-mediated inactivation of $\mathrm{Ca}^{2+}$ influx (e.g., Eckert and Tillotson, 1981), which has recently been found to occur in hippocampal cells during repetitive activation (Pitler and Landfield, 1987b). The inactivation of $\mathrm{Ca}^{2+}$ currents in terminals could lead to decreased release of vesicles (and synaptic depression), even if synaptic vesicles were not depleted.

A third possibility, particularly in the case of $40 \mathrm{~Hz}$ stimulation, is that action potential invasion might fail in some terminals, which could contribute to synaptic depression (e.g., Smith, 1980; Hirst et al., 1981). Again, in this instance vesicles would not necessarily be depleted in conjunction with the depression.

Assessing the effects of these several possible confounding factors on vesicle/physiology correlations will require further analyses under conditions in which more direct recording of synaptic function is possible, and in which potentiation, synaptic depression, and vesicle recycling can be altered more systematically.

\section{Distant vesicles and "recycling"}

Conceivably, the infoldings seen during $40 \mathrm{~Hz}$ (Fig. 5) or $10 \mathrm{~Hz}$ (Fig. $4 B$ ) are analogous to the "cisternae" observed by Heuser and Reese (1973) and Model et al. (1975), and represent a source of vesicle recycling. Since they were gencrally found at sites removed from the active zone, infoldings may "feed" recycled vesicles into the DV population. Hippocampal frequency potentiation was correlated in time with increases in the LVD, the LVD:DVD, and the AV. However, across individual animals, the DVD was the morphometric variable most closely correlated with the degree of spike potentiation/depression. If the DVD is in some way linked to the efficacy of recycling, then the correlation of DVD and spike amplitude may indicate that redistribution (increased LVD:DVD) and an increased probability of attachment (AV) are unable to maintain increased synaptic function during repetitive activity without a steady replenishment of "reserve" vesicles (e.g., of the DV).

\section{Effects of age on vesicle patterns}

Several effects of age were found in this study, including (1) a reduced density of DV, primarily in the control condition; (2) an increased LVD:DVD in the control condition; and (3) a reduced increase in attached vesicles at $1 \mathrm{~min}$ of $10 \mathrm{~Hz}$ stimulation. In addition, the pattern of spine changes differed with age. However, except for the reduced DVD in the control condition, no age differences in vesicle density were seen.

Although the functional implications of a reduction in resting DVD, if any, are not clear, the lack of an increase in AV at 1 min of $10 \mathrm{~Hz}$ seems to be a reasonable candidate for an ultrastructural correlate of the age-related impairment of frequency potentiation. That is, under current views of vesicle dynamics, attached vesicles would be more likely to release their contents (cf. Heuser and Reese, 1977).

The lack of an age-related difference on any measure of vesicle density at any stimulation point suggests that a simple reduction in vesicle number is not the major factor in the age-related impairment. Instead, the age-related impairment of potentiation could result from a reduced rate of vesicle release (perhaps manifested in a reduced AV) and/or cycling, or might not depend on vesicle patterns to any significant extent. Therefore, the functional deficit may not correlate highly with measures of vesicle density alone.

One possible explanation of the data might lie in the finding that hippocampal neurons from aged animals seem to exhibit greater calcium influx into cell bodies for a given depolarization (Landfield and Pitler, 1984, 1987). If $\mathrm{Ca}^{2+}$ influx into terminals is also increased with age (cf. Landfield et al., 1986), such increased influx could account for the apparently greater activation (higher LVD:DVD) and reduced vesicle reserves (lower DVD) seen in aged neurons in the resting control condition. Increased leakage of transmitter, which has been seen at neuromuscular terminals of aged rats (Smith, 1984), might also result from elevated $\mathrm{Ca}^{2+}$, or may be a factor in decreased resting vesicle content. With the onset of repetitive synaptic stimulation, increased $\mathrm{Ca}^{2+}$ influx into terminals could lead to greater activation of $\mathrm{Ca}^{2+}$-dependent $\mathrm{K}^{+}$-mediated hyperpolarization (e.g., Landfield and Pitler, 1984), and resultant failure of action potential conduction (e.g., Smith, 1980; Hirst et al., 1981). Alternatively, the initially increased $\mathrm{Ca}^{2+}$ influx into terminals could lead to greater $\mathrm{Ca}^{2+}$-mediated inactivation of $\mathrm{Ca}^{2+}$ currents and, subsequently, to reduced $\mathrm{Ca}^{2+}$ influx (Pitler and Landfield, 1987b). Either effect might result in reduced release (and fewer AV), without a reduction in vesicle density. Of course, other explanations are possible (e.g., postsynaptic changes, technical difficulties in precisely measuring vesicle densities and synaptic function, among others), and additional research will clearly be needed to determine whether the ultrastructural patterns observed here reflect transmitter release processes important in normal or impaired information processing.

\section{References}

Alger, B. E., and T. J. Teyler (1978) Potassium and short-term response plasticity in the hippocampal slice. Brain Res. 159: 239-242.

Andersen, P. (1975) Organization of hippocampal neurons and their interconnections. In The Hippocampus, vol. 1, R. L. Isaacson and $\mathrm{K}$. H. Pribram, eds., pp. 155-175, Plenum, New York.

Andersen, P., and T. Lomo (1967) Control of hippocampal output by afferent volley frequency. In Progress in Brain Research: Structure and Function of the Limbic System, vol. 27, W. R. Adey and T. Tokizane, eds., pp. 400-412, Elsevier, Amsterdam.

Applegate, M. D., and P. W. Landfield (1985) Vesicle mobilization and depletion during frequency potentiation and depression in the hippocampus of aged and young rats. Soc. Neurosci. Abstr. 11: 895 .

Applegate, M. D., D. S. Kerr, and P. W. Landfield (1987) Redistribution of synaptic vesicles during hippocampal long-term potentiation. Brain Res. 401: 401-406.

Arenberg, D., and E. A. Robertson-Tchabo (1977) Learning and aging. In Handbook of the Psychology of Aging, J. E. Birren and K. W. Schaie, eds., pp. 421-499, Von Nostrand Reinhold, New York.

Bliss, T. V. P., and T. Lømo (1973) Long-lasting potentiation of synaptic transmission in the dentate area of the anaesthetized rabbit following stimulation of the perforant path. J. Physiol. (Iond.) 232: 331-356.

Brown, T. H., and D. Johnston (1983) Voltage-clamp analysis of mossy fiber synaptic input to hippocampal neurons. J. Neurophysiol. 50: 487-503. 
Brown, T. H., D. H. Perkel, and M. W. Feldman (1976) Evoked neurotransmitter release: Statistical effects of nonuniformity and nonstationarity. Proc. Natl. Acad. Sci. USA 73: 2913-2917.

Ceccarelli, B., and W. P. Hurlbut (1980) Vesicle hypothesis of the release of quanta of acetylcholine. Physiol. Rev. 60: 396-441.

Chang, F. L. F., and W. T. Greenough (1984) Transient and enduring morphological correlates of synaptic activity and efficacy change in the rat hippocampal slice. Brain Res. 309: 35-46.

Deadwyler, S. A. J. Biela, G. Rose, M. O. West, and G. S. Lynch (1979) A microdrive for use with glass or metal microelectrodes in recording from freely-moving rats. EEG Clin. Neurophysiol. 47: 752-754.

Desmond, N. L., and W. B. Levy (1983) Synaptic associative potentiation/depression: An ultrastructural study in the hippocampus. Brain Res. 265: 21-30.

Desmond, N. L., and W. B. Levy (1986) More front-line synaptic vesicles with long-term synaptic potentiation in the hippocampal dentate gyrus. Soc. Neurosci. Abstr. 12: 504.

Dickinson-Nelson, A., and T. S. Reese (1983) Structural changes during transmitter release at synapses in the frog sympathetic ganglion. J. Neurosci. 3: 42-52.

Eckert, R., and D. L. Tillotson (1981) Calcium-mediated inactivation of the calcium conductance in caesium-loaded giant neurones of $A p l y$ sia california. J. Physiol. (Lond.) 314: 265-280.

Fahim, M. A., and N. Robbins (1982) Ultrastructural studies of young and old mouse neuromuscular junctions. J. Neurocytol. 11: 641-656.

Fehér, O., F. Joó, and N. Halász (1972) Effect of stimulation on the number of synaptic vesicles in nerve fibres and terminals of the cerebral cortex in the cat. Brain Res. 47: 37-48.

Fifkova, E., and K. Cullen-Dockstader (1986) Age-related changes in the distribution of calcium-containing synaptic vesicles in terminals of the perforant path. Soc. Neurosci. Abstr. 12: 271.

Fifkova, E., and A. Van Harreveld (1977) Long-lasting morphological changes in dendritic spines of dentate granular cells following stimulation of the entorhinal area. J. Neurocytol. 6: 211-230.

Gottlieb, D. I., and W. M. Cowan (1973) Autoradiographic studies of the commissural and ipsilateral association connections of the hippocampus and dentate gyrus of the rat. I. The commissural connections. J. Comp. Neurol. 149: 393-422.

Haimann, C., F. Torri-Tarelli, R. Fesce, and B. Ceccarelli (1985) Measurement of quantal secretion induced by ouabain and its correlation with depletion of synaptic vesicles. J. Cell Biol. 101: 1953-1965.

Heuser, J. E., and T. S. Reese (1973) Evidence for recycling of synaptic vesicle membrane during transmitter release at the frog neuromuscular junction. J. Cell Biol. 57: 315-344.

Heuser, J. E., and T. S. Reese (1977) Structure of the synapse. In Handbook of Physiology. 1: The Nervous System, J. M. Brookhart and V. B. Mountcastle, eds., pp. 262-294, American Physiological Society, Bethesda, MD.

Hirst, G. D., S. J. Redman, and K. Wong (1981) Post-tetanic potentiation and facilitation of synaptic potentials evoked in cat spinal motoneurones. J. Physiol. (Lond.) 321: 97-109.

Hjorth-Simonsen, A. (1972) Projection of the lateral part of the entorhinal area to the hippocampus and fascia dentata. J. Comp. Neurol 146: 219-232.

Humphrey, D. R. (1968) Re-analysis of the antidromic cortical response II. On the contribution of cell discharge and PSPs to the evoked potentials. EEG Clin. Neurophysiol. 25: 421-442.

Jones, S. F., and S. Kwanbunbumpen (1970) The effects of nerve stimulation and hemicholinium on synaptic vesicles at the mammalian neuromuscular junction. J. Physiol. (Lond.) 207: 31-50.

Katz, B. (1962) The transmission of impulses from nerve to muscle, and the subcellular unit of synaptic action. Proc. R. Soc. Lond. [Biol.] 155: 455-477.

Kuno, M. (1964) Mechanism of facilitation and depression of the excitatory synaptic potential in spinal motoneurones. J. Physiol. (Lond.) 175: $100-112$.

Landfield, P. W., and T. A. Pitler (1984) Prolonged $\mathrm{Ca}^{2+}$-dependent afteihyperpolarizations in hippocampal neurons of aged rats. Science 226: $1089-1092$

Landfield, P. W., and T. A. Pitler (1987) Increased duration of calcium spikes in hippocampal neurons of aged rats. Soc. Neurosci. Abstr. 13: 718.

Landfield, P. W., J. L. McGaugh, and G. Lynch (1978) Impaired synaptic potentiation processes in the hippocampus of aged, memorydeficient rats. Brain Res. 150: 85-101.
Landfield, P. W., C. Wurlz, and J. D. Lindsey (1979) Quantification of synaptic vesicles in hippocampus of aging rats and initial studies of possible relations to neurophysiology. Brain Res. Bull. 4: 757-763.

Landtield, P. W., T. A. Pitler, M. D. Applegate, and J. H. Robinson (1983) Intracellular studies of the age-related deficit in hippocampal frequency potentiation: Apparent calcium saturation in synapses of aged rats. Soc. Neurosci. Abstr. 9: 232.

Landfield, P. W., T. A. Pitler, and M. D. Applegate (1986) The effects of high $\mathrm{Mg}^{2+}-10-\mathrm{Ca}^{2+}$ ratios on frequency potentiation in hippocampal slices of young and aged rats. J. Neurophysiol. 56: 797-811.

Langmeier, M., L. Mares, and J. Fischer (1983) Number of synaptic vesicles in rat cortex immediately after cessation of the self-sustained afterdischarge during kindling. Epilepsia 24: 616-627.

Lee, K. S., F. Schottler, M. Oliver, and G. Lynch (1980) Brief bursts of high frequency stimulation produce two types of structural change in rat hippocampus. J. Neurophysiol. 44: 247-248.

Lynch, G., and M. Baudry (1984) The biochemistry of memory: A new and specitic hypothesis. Science 224: 1057-1063.

MacVicar, B. A., and F. E. Dudek (1979) Intracellular recordings from hippocampal CA3 pyramidal cells during repetitive activation of mossy fibers in vitro. Brain Res. 168: 377-381.

Maler, L., and W. B. Mathieson (1985) The effect of nerve activity on the distribution of synaptic vesicles. Cell. Mol. Neurobiol. 5:373387.

Martin, A. R. (1977) Presynaptic mechanisms. In Handbook of Physiology. I: The Nervous System, J. M. Brookhart and V. B. Mountcastle, eds., pp. 329-355, American Physiological Society, Bethesda, MD.

McCarren, M., and B. E. Alger (1985) Use-dependent depression of IPSPs in rat hippocampal pyramidal cells in vitro. J. Neurophysiol 53: 557-571.

McNaughton, B. L., C. A. Barnes, and P. Andersen (1981) Synaptic efficacy and EPSP summation in granule cells of rat fascia dentata studied in vitro. J. Neurophysiol. 46: 952-966.

Mendell, L. M., and R. Weiner (1976) Analysis of pairs of individual 1a-E.P.S.P.s in single motoneurones. J. Physiol. (Lond.) 255: 81-104.

Model, P. G., S. M. Highstein, and M. V. L. Bennett (1975) Depletion of vesicles and fatigue of transmission at a vertebrate central synapse. Brain Res. 98: 209-228.

Neale, E. A., P. G. Nelson, R. L. McDonald, C. N. Christian, and L. M. Bowers (1983) Synaptic interactions between mammalian central neurons in cell culture. III. Morphophysiological correlates of quantal synaptic transmission. J. Neurophysiol. 49: 1459-1468.

Peters, A., S. L. Palay, and H. D. Webster (1976) The Fine Structure of the Nervous System, Saunders, Philadelphia, PA.

Pitler, T. A., and P. W. Landfield (1987a) Postsynaptic membrane shifts during frequency potentiation of the hippocampal EPSP. J. Neurophysiol. 58: 866-882.

Pitler, T. A., and P. W. Landfield (1987b) Probable $\mathrm{Ca}^{2+}$-mediated inactivation of $\mathrm{Ca}^{2+}$ currents in mammalian brain neurons. Brain. Res. 410:147-153.

Prince, D. A., H. D. Lux, and E. Neher (1973) Measurement of extracellular potassium activity in cat cortex. Brain Res. 50: 489-495.

Pysh, J. J., and R. G. Wiley (1974) Synaptic vesicle depletion and recovery in cat sympathetic ganglia electrically stimulated in vivo: Evidence for transmitter secretion by exocytosis. J. Cell Biol. 60:365374.

Quilliam, J. P., and D. L. Tamarind (1973) Local vesicle populations in rat superior cervical ganglia and the vesicle hypothesis. J. Neurocytol. $2: 59-75$.

Rall, W., and J. Rinzel (1973) Branch input resistance and steady attenuation for input to one branch of a dendritic neuron model. Biophys. J. 13: 648-688.

Rall, W., and G. M. Shepherd (1968) Theoretical reconstruction of field potentials and dendrodendritic synaptic interactions in olfactory bulbs. I. Neurophysiol. 31: 884-915.

Schwartzkroin, P. A. (1975) Characteristics of CAl neurons recorded intracellularly in the hippocampal in vitro slice preparation. Brain Res. 85 : 423-436.

Smith, D. O. (1980) Mechanisms of action potential propagation failure at sites of axon branching in the crayfish. J. Physiol. (London.) 301: $243-259$.

Smith, D. O. (1984) Acetylcholine storage, release and leakage at the neuromuscular junction of mature adult and aged rats. J. Physiol. (Lond.) 347: 161-176.

Smith, D. O., and J. L. Rosenheimer (1982) Decreased sprouting and 
degeneration of nerve terminals of active muscles in aged rats. J. Neurophysiol. 48: 100-109.

Steward, O. (1976) Topographic organization of the projections from the entorhinal area to the hippocampal formation of the rat. J. Comp. Neurol. 167: 285-314.

Swanson, L. W., J. M. Wyss, and W. M. Cowan (1978) An autoradiographic study of the organization of intrahippocampal association pathways in the rat. J. Comp. Neurol. 181: 681-716.

Tauc, L. (1982) Nonvesicular release of neurotransmitter. Physiol. Rev. 62: 857-893.

Torri-Tarelli, F., F. Grohovaz, R. Fesce, and B. Ceccarelli (1985) Temporal coincidence between synaptic vesicle fusion and quantal secretion of acetylcholine. J. Cell Biol. 101: 1386-1399.

Turner, D. A. (1988) Waveform and amplitude characteristics of evoked responses to dendritic stimulation of guinea pig CA1 pyramidal cells. J. Physiol. (I ond.) 395: 419-439.
Weibel, E. R. (1979) Stereological Methods. Vol. 1: Practical Methods for Riological Morphometry, Academic, New York.

Wilson, R. C., W. B. Levy, and O. Steward (1981) Changes in translation of synaptic excitation to dentate granule cell discharge accompanying long-term potentiation. II. An evaluation of mechanisms utilizing dentate gyrus dually innervated by surviving ipsilateral and sprouted crossed temporodentate inputs. J. Neurophysiol. 46: 339_ 355.

Zimmerman, H., and C. R. Denston (1977) Recycling of synaptic vesicles in the cholinergic synapses of the Torpedo electric organ during induced transmitter release. Neuroscience 2: 695-714.

Zucker, R. S. (1973) Changes in the statistics of transmitter release during facilitation. J. Physiol. (Lond.) 229: 787-810. 